\title{
Neighborhood Effects in Integrated Social Policies*
}

\author{
Matteo Bobba $\quad$ Jérémie Gignoux ${ }^{\ddagger}$
}

August 2016

\begin{abstract}
When potential beneficiaries share their knowledge and attitudes about a policy intervention, their decision to participate and the effectiveness of both the policy and its evaluation may be influenced. This matters most notably in integrated social policies with several components. We examine spillover effects on take-up behaviors in the context of a conditional cash transfer program in rural Mexico. We exploit exogenous variations in the local frequency of beneficiaries generated by the program's randomized evaluation. A higher treatment density in the areas surrounding the evaluation villages increases the take-up of scholarships and enrollment at the lower-secondary level. These cross-village spillovers operate exclusively within households receiving another component of the program, and do not carry over larger distances. While several tests reject heterogeneities in impact due to spatial variations in program implementation, we find evidence to suggest that spillovers stem partly from the sharing of information about the program among eligible households.
\end{abstract}

Keywords: take-up; social policy; spatial externalities; knowledge spillovers; policy evaluation; conditional cash transfers.

JEL Codes: C9, I2, J2, O2.

${ }^{*}$ This draft supersedes previous versions circulated under the title: "Spatial Externalities and Social Multipliers in Schooling Interventions" and "Policy Induced Social Interactions". We are grateful to the Editor and three referees for the insightful comments that greatly improved the paper. We have also benefitted from discussions with Orazio Attanasio, Samuel Berlinski, François Bourguignon, Giacomo De Giorgi, Pierre Dubois, Marc Gurgand, Sylvie Lambert, Karen Macours, Eliana La Ferrara, Imran Rasul, and Martin Ravallion, as well as with audiences at various seminars, conferences and workshops. We also thank Marco Pariguana for excellent research assistance and the Secretaría de Educación Publica (Mexico), the Oportunidades Staff, and in particular Raul Perez Argumedo for their kind help with the datasets.

${ }^{\dagger}$ Toulouse School of Economics, University of Toulouse Capitole, 21 Allée de Brienne 31000 Toulouse France. E-mail: matteo.bobba@tse-fr.eu.

${ }_{\ddagger}^{\ddagger}$ Paris School of Economics (INRA), 48 boulevard Jourdan 75014 Paris France. E-mail: gignoux@pse.ens.fr. 


\section{Introduction}

Demand-side schooling interventions have now become an important component of social policies in developing countries. The available empirical evidence suggests that cash subsidies in particular can have a large effect on schooling decisions (e.g., Glewwe \& Kremer 2006). These interventions have been found to be effective devices for encouraging the human capital investments of poor households (e.g., Parker et al. 2008 and Fiszbein \& Schady 2009). Recent studies have documented that they can also induce a set of non-market interactions that can further increase their effects (Angelucci et al. 2010, Bobonis \& Finan 2009, and Lalive \& Cattaneo 2009). Social interactions affecting preferences for investments in education and transfers within extended families have, in particular, been posited and documented. However, there is still incomplete knowledge of the specific networks within which those interactions occur and the underlying mechanisms at play.

The sharing of knowledge and attitudes about policy interventions among networks of potential beneficiaries is one set of social interaction that remains under-documented in the setting of social policies in developing countries. The role of information-sharing and initial preferences and prejudices in determining program participation has been emphasized in the context of social policies in the United States. For instance, Bertrand et al. (2000) and Aizer \& Currie (2004) find evidence of networks effects, i.e., correlations in program take-up decisions within neighborhoods and ethnic groups. In the case of the Food Stamp Program, Daponte et al. (1999) find that ignorance about the program contributes to non-participation.

The conditional cash transfer (CCT) programs that have been recently implemented in developing countries create many opportunities for knowledge spillovers between beneficiaries. These opportunities are likely to affect the take-up of some subsidies, notably schooling subsidies, and are influenced by three types of factors that span both supply and demand sides. First, in integrated social policies, cash subsidies for schooling tend to be associated with complementary interventions for the provision of health care or support for better nutrition. Beneficiaries do not necessarily participate in all interventions, so that there is an intensive margin for potential recipients to increase their participation in the program by taking up more components. Second, the recipients of the transfers, notably women and mothers, regularly encounter each other during program operations, for instance in meetings of beneficiaries or during activities of complementary interventions, such as visits to health centers. Third, the targeting of those interventions implies that participants often have similar socioeconomic backgrounds and are thus likely to identify with each other (Akerlof 1997). Hence, demand-side schooling interventions are likely to both enhance the existing 
interactions among groups of beneficiaries, and to further shape those groups, thus producing externalities that would not occur were individuals treated in isolation.

In this paper, we examine the role of spillover effects, in the form of information sharing within networks of potential beneficiaries, and in shaping the take-up of the schooling subsidy component of the Progresa-Oportunidades CCT program (see, e.g., Schultz 2004, and Parker et al. 2008). The program entails several unbundled components in addition to the schooling subsidies, notably food stipends conditional on health checks. While the take-up of the nutrition and health component is almost 100 percent, a large share of children eligible for transfers for secondary schooling remain un-enrolled.

The program targets poor households in small villages located in rural areas of Mexico. Due to the high level of program penetration and geographic targeting, the topography of the area covered by the program consists of clusters of neighboring villages with a high density of beneficiary households. In this context, program beneficiaries living in neighboring villages are likely to interact in several ways, thereby potentially sharing information about the program. In order to examine the effects of those interactions, we investigate the extent to which variations in the local frequency of the program in areas surrounding beneficiary villages affects the take-up response of potential beneficiaries.

Spillovers have previously been examined in the context of Progresa - Oportunidades by comparing the outcomes of ineligible and eligible households in the same villages by means of a partial-population design (Moffitt 2001). Accordingly, Bobonis \& Finan (2009) and Lalive \& Cattaneo (2009) have found evidence of spillovers through peer effects in school enrollment, and Angelucci \& De Giorgi (2009), Angelucci et al. (2010) and Angelucci et al. (2012) provide evidence of transfers within both village and household-level networks. ${ }^{1}$ However, in the Progresa-Oportunidades setting many beneficiary communities are very close to each other, thus spillovers may occur not only within but also across villages.

To investigate the presence of neighborhood effects, we combine data from the experimental evaluation of the program with information on the geo-referenced locations of the villages benefitting from it. We focus our analysis on the secondary school participation decisions of program-eligible children, which is the primary short-run outcome of the intervention and the key requirement associated with the largest component of the in-cash transfer.

We use a simple empirical framework that allows us to disentangle the effects of the incentives resulting from the program eligibility of the household (and the village it resides

\footnotetext{
${ }^{1}$ Other recent examples from the literature include Duflo \& Saez (2003) who examine the take-up of retirement plans within academic departments, and Kuhn et al. (2011) who study spillover effects of lottery winnings within Dutch postal codes.
} 
in) from the indirect effects arising from the local density of program recipients at the level of areas surrounding targeted villages. In particular, we exploit the randomized evaluation design and the clustered spatial distribution of the villages in our sample in order to identify the causal effects of program externalities generated by those neighboring villages selected in the experimental treatment group. Next, we investigate whether spillovers arise in this setting because of social interactions between program beneficiaries, or as a result of other changes associated with variations in the local density of the program across areas surrounding villages.

We find evidence of a positive effect of the local frequency of participants in the program over short distances $(0-5 \mathrm{~km})$ on secondary school participation decisions, which tend to quickly dissipate at larger distances $(5-10 \mathrm{~km})$. Such a spillover effect does not increase linearly with the number of treated villages, with estimated effects of, respectively, one or two or more treated villages in the neighboring area on secondary school enrollment of 6.1 and 8.0 percent. The magnitude of the indirect effect of the program is substantial when compared to the direct effect of own village treatment of 9.7 percent.

Crucially, these spatial externalities appear to exclusively affect children from beneficiary households; there is no evidence of such effects for children in the control group and for those in treated villages who are not eligible for the program. This remarkable heterogeneity sheds light on the mechanisms behind program externalities. Interactions within networks of potential beneficiaries spanning across villages seem to have contributed to increase the takeup of the educational component of the program and heighten its impacts on schooling. We argue that, while interactions through preexisting social networks should affect all households that share local resources, social interactions that are restricted to program beneficiaries are likely to be associated with knowledge and attitudes toward the program. Accordingly, we find that our variation in local treatment frequency is associated with increased knowledge among eligible households, about the different components of the program - notably the schooling subsidies.

Some sort of spatial variation in the delivery of the program among evaluation villages could, in principle, explain the observed relationship between the local density of treatment and the take-up of schooling subsidies. This may occur if, for instance, areas with more evaluation villages benefit from more efficient program operations, or receive larger investments in supply infrastructure, thereby helping recipients comply with the schooling requirements of the program. However, using direct measures of efficiency of program operations or schooling infrastructures, we find little support in the data for this alternative interpretation. 
Our results thus provide evidence of the effect of the local frequency of treatment on the take-up of the different components of social policies. We find evidence to suggest that knowledge spillovers among networks of beneficiaries is likely to be driving those effects. Our findings also relate to other studies which have used experimental variations of treatment frequency to identify the effects of the spillover of interventions (e.g., Miguel \& Kremer 2004, Banerjee et al. 2010, and Ichino \& Schundeln 2012). However, those studies were conducted during small-scale interventions, and hence potentially miss important effects that occur during the full-scale implementation of a program. ${ }^{2}$ Our results shed light on those scalingup effects by examining spatial externalities in an experimental sample surveyed in the midst of the implementation of the policy on a large scale.

\section{Setting and Data}

\subsection{Program features}

Initiated in 1997 and still in effect, Progresa-Oportunidades is a large-scale social program that aims to foster the accumulation of human capital in the poorest communities of Mexico by providing both cash and in-kind benefits in the key areas of health and education, which are conditional on specific behaviors. The program grants scholarships and school supplies to children aged under 17, conditional on regular attendance at one of the four last grades of primary schooling (grades 3 to 6 ) or one of the three grades of junior secondary schooling (grades 7 to 9). The scholarships increase in amount with school grade level achieved, and in grades 7 to 9 the scholarships are larger for girls than boys. The program also distributes cash transfers for the purchase of food, provides food supplements, and promotes health care through free preventive education intervention on hygiene and nutrition. The distribution of the food stipends and nutritional supplements are conditional on health care visits at public clinics. The benefits are delivered to the female head of the household (usually the mother) on a bimonthly basis after verification of each family member's attendance at the relevant facility. ${ }^{3}$

The Progresa program is targeted both at the village and household levels. During the first years of the program, poor rural households were selected through a centralized process

\footnotetext{
${ }^{2}$ To partially overcome this issue, researchers have recently begun to inject experimental variations directly into the intensity of spillover effects by varying the saturation of individuals treated within treated clusters (Baird et al. 2014, Crepon et al. 2013).

${ }^{3}$ Overall cash transfer amounts can be substantial: the median benefits are 176 pesos per month (roughly 18 USD in 1998), equivalent to about 28 percent of the monthly income of beneficiary families.
} 
which encompassed three main steps. First, villages were ranked by a composite index of marginality, computed using information on socioeconomic characteristics and access to the program infrastructures from the censuses of 1990 and 1995. ${ }^{4}$ Second, potentially eligible localities were grouped based on geographical proximity, and relatively isolated communities were excluded from the selection process. Third, eligible households were selected using information on covariates of poverty obtained from a field census conducted in each locality before its incorporation into the program. ${ }^{5}$

The program started in 1997 in 6,300 localities with about 300,000 beneficiary households, and expanded rapidly during the following years. In 1998, it was delivered to 34,400 localities (1.6 million households), and in 1999, coverage increased to 48,700 localities (2.3 million households). The expansion of the program continued in subsequent years, both in rural and urban areas.

An experimental evaluation of the program was conducted during this phase of geographical expansion in rural areas. A sample of 506 villages was randomly drawn from a set of localities that had been selected to be incorporated into the program, and were located in seven central states of Mexico (Guerrero, Hidalgo, Queretaro, Michoacan, Puebla, San Luis de Potosi, and Veracruz), after stratification by geographic region (which coincide roughly with the States) and population size. The randomness of the evaluation sample is corroborated in a supplemental appendix (Section A). We document in particular that evaluation localities do not have different observable characteristics compared to non-evaluation localities located in the same neighborhoods. Also, the characteristics of evaluation localities and their population are not statistically significantly associated with the number of evaluation localities once the number of non-evaluation localities in their neighborhood are controlled for. Of those villages, 320 localities were randomly assigned to the treatment group and started receiving the program's benefits in March-April 1998; the remaining 186 formed the control group and were thus prevented from receiving the program benefits until November 1999.

\footnotetext{
${ }^{4}$ Localities with fewer than 50 or more than 2,500 inhabitants were excluded during the first years of the program. We use the words "locality" and "village" interchangeably when referring to distinct censusdesignated rural population clusters, i.e., settlements in which inhabitants live in neighboring sets of living quarters and have a name and locally recognized status (including hamlets, villages, farms, and other clusters). Rural localities (also called rural communities), or villages, are defined as having fewer than 2,500 inhabitants.

${ }^{5} \mathrm{~A}$ proxy-mean index was computed as a weighted average of household income (excluding children), household size, durables, land and livestock, education, and other physical characteristics of the dwelling. Households were informed that their eligibility status would not change until at least November 1999, irrespective of any variation in household income.
} 


\subsection{Program take-up}

Importantly for our purposes, the two transfer components are unbundled. Households declared eligible to receive benefits can take up food stipends, scholarships, or both. They can also choose to receive the scholarships for some but not all of their eligible children. Beyond transfer amounts, take-up decisions are largely dependent on the tightness of the conditions attached to each grant component. While nominally conditional, a substantial fraction of the transfers is de facto unconditional. In particular, the conditions attached to the food stipends and scholarships for primary school children do not seem to incur a high cost to households, because school enrollment at that level is almost 100 percent. We use data to document take-up from the administration of the program on the distribution of the different transfers in the 320 treatment localities of the evaluation. This data confirms the complete take-up of the food stipends: at the end of 1998 and 1999, respectively 97.1 and 98.0 percent of eligible households in those localities received the transfers.

In contrast, the conditionality of the scholarships at the secondary level is binding for many households whose eligible school-age children would not have gone to school in the absence of the program. The same data indicates that, respectively, 83.0 and 91.3 percent of households that are eligible for a scholarship for at least one child enrolled at the primary or secondary level received one. However, only 63.7 percent of children who were eligible for a scholarship for secondary-level school attended school in 1998, with 61.9 percent attending in 1999 .

Hence, partial take-up of the program benefits is prevalent in this setting, whereby some eligible households comply with the food stipend conditions but refrain from enrolling some

or all of their children in secondary school. However, once they are incorporated into the program, recipients can further adjust their behavior by enrolling some of their programeligible children. While take-up of the food transfers is almost complete, there is thus a margin for increasing the take-up of the schooling component, which can be seen as an intensive margin of program participation.

\subsection{Village neighborhoods}

In this paper, we use the term 'neighborhood' to describe areas within a given radius around each evaluation village. We borrow this terminology from a literature based mainly on urban data, but in our context, 'neighborhood' means an area or cluster of villages.

In order to characterize the local densities of the intervention (in the neighborhoods), 
we combine information from the program administration, indicating which localities were eligible for the program at the end of 1998 and 1999, with information from the 2000 population census and the annual school census. The population census provides the geographical coordinates (latitudes and longitudes) for all the rural localities in Mexico, while the school census provides the coordinates of all secondary schools. The geo-referenced data further allows us to identify the locations of the evaluation localities. ${ }^{6}$

As in many rural regions of Latin America and elsewhere, the topography of the area covered by the program consists of clusters of villages with a quasi-continuum of dwellings, rather than isolated villages. On average, there are 22 localities with an overall population of roughly 6,400 inhabitants within an area defined by a $5 \mathrm{~km}$ radius from each evaluation village. This proximity favors the interactions between inhabitants of neighboring villages.

Looking now at the intervention, Figure 1 depicts the geographic scope of the Progresa penetration during the first two years of program roll-out in the seven central states where the evaluation took place. The rural localities targeted by the program in 1998 and 1999 are shown in light and dark grey respectively, while treatment and control localities are reported in red and blue. In order to provide a more in-depth depiction of the areas surrounding evaluation villages, the map features a smaller-scale view of a region in the State of Michoacan in which circles of $5 \mathrm{~km}$ radius are drawn around each evaluation village.

Both maps reveal that beneficiary and evaluation villages tend to be geographically clustered - with more deprived areas featuring a higher program frequency. These patterns are confirmed by descriptive statistics of the areas surrounding the evaluation sample, which are shown in Table 1. By the end of 1998, there are on average 10 program-beneficiary localities within a neighborhood defined by a $5 \mathrm{~km}$ radius around each evaluation village. Those localities have an average total population of 834 children aged 6 to 14, of which on average 386 (46 percent) receive scholarships from Progresa (column 1). ${ }^{7}$ Moreover, several evaluation villages are indeed located very close together. Of the 506 evaluation localities, 139 (27 percent) have another evaluation locality within $5 \mathrm{~km}, 57$ (11 percent) have two such localities, and 16 (3 percent) have three or more. Thus, 212 (41 percent) villages in the

\footnotetext{
${ }^{6}$ We have used official information on the listing of all rural localities receiving the program (broken down by each program component) at the closing of each fiscal year in 1998 and 1999 in order to verify which localities were receiving the program in late 1998 and 1999. A fraction (about 20 percent) of control localities started receiving the program's food stipends by November 1999, but none of those villages had received any scholarship by that date. We thus continue to treat those observations as belonging to the control group in November 1999.

${ }^{7}$ Evaluation villages tend to be less populated than non-evaluation villages (average total population in the two groups is 258 and 338, respectively), while the marginalization index is on average very similar (4.66 vs. 4.72, respectively). Accordingly, there are on average slightly more scholarship recipients in nonevaluation villages (49.2) than in evaluation villages (34.5).
} 
experiment have other evaluation villages in a $5 \mathrm{~km}$ radius. Our empirical analysis identifies the effects of cross-village externalities for these villages. On average, evaluation villages have, respectively, 0.62 other evaluation localities, and 0.40 localities allocated to the experimental treatment group, within a $5 \mathrm{~km}$ radius. The density of the program, as captured by the numbers of both non-evaluation and evaluation beneficiary villages, roughly doubles in areas, with more marginalized localities (columns 2-3). This is consistent with the targeting design of the Progresa intervention discussed above. In addition, and as expected by the village-level random program assignment among the evaluation localities, there are virtually no differences in the density of the program between neighborhoods with treated or control centroids (columns 4-5).

Basic education and health infrastructures serve areas that comprise several neighboring villages. For instance, only 14 percent of the villages in the evaluation sample have a health clinic. Yet, 68 percent have access to such a facility within $5 \mathrm{~km}$. Similarly, most localities do not have a junior secondary school - only 17 percent in the evaluation sample - while 93 percent have access to one or more junior secondary schools in other villages within $5 \mathrm{~km}$. Hence, households from different program localities located in the same area can interact when utilizing social infrastructure. Furthermore, some operations which are specific to the program are also organized in conjunction for several neighboring villages. This is most notably the case of the distribution of transfers in temporary and mobile outposts - located in hub localities - which serve an additional function to assist beneficiaries and disseminate information on the program. Hence, program beneficiaries from different neighboring villages can interact in a number of places.

\subsection{Sample description}

We combine the geo-referenced locality data mentioned above with three of the five rounds of the evaluation survey, collected in October 1997 (from the baseline targeting ENCASEH survey), October 1998 (second round of the ENCEL evaluation surveys), and November 1999 (fourth round of the ENCEL surveys). ${ }^{8}$ The resulting dataset contains detailed information on the outcomes of children and socioeconomic characteristics of a panel of households that reside within the evaluation localities.

The evaluation survey was intended to cover all inhabitants of the localities under study. However, a small share of the population was not interviewed at baseline, and there were

${ }^{8}$ We have discarded the March 1998 and June 1999 rounds of the survey because we only have information on the roll-out of the program at the end of each year. 
some changes in the village populations, so the total number of households observed in the data is 24,077 in October 1997, 25,846 in October 1998, and 26,972 in November 1999. Some attrition occurred, due in part to migration out of the villages, and in part to errors in identification codes that occurred for a few enumerators: 8.4 percent of the 1997 households cannot be followed and matched in all three rounds of the survey. Yet, this is unrelated to the treatment assignment.

At baseline (October 1997), 60 percent of the households in evaluation localities were classified as eligible to receive program benefits. In this paper, we study the schooling decisions of the children of those eligible households. ${ }^{9}$ Our main outcome of interest is school enrollment, for which we also use the term "school participation" interchangeably. This answers the question, Does the child currently attend school?, which tracks information regarding both enrollment and overall attendance in school (but not regular attendance). Primary school enrollment is almost universal in rural Mexico, while secondary school enrollment is the most problematic area for school attainment. Also, secondary grade levels are where Progresa has had its greatest impact among eligible children (Schultz 2004). We thus restrict our attention to the enrollment decisions of children who, at baseline, are aged less than 18 and have either completed grades 5 or 6 of primary school or the first grade of secondary school. ${ }^{10}$ We further reduce the number of observations in the data in order to generate a balanced panel of children observed at all rounds.

The resulting sample contains 6,690 children who are making the transition from primary to secondary school, remaining in secondary education or dropping out of school during the academic years 1998-1999 and 1999-2000. For 807 (12.6 percent) of children, no information was collected on either school participation or parental education, thereby leaving a final sample of 5,883 children observed in both 1998 and 1999. At baseline, the average enrollment rate is 63.8 percent (59.3 percent for girls and 68.5 percent for boys).

\section{Program Externalities Across Villages}

\subsection{Empirical strategy}

Our identification strategy exploits two features of the program evaluation design: the proximity between many evaluation villages, and village-level random assignment to treatment.

\footnotetext{
${ }^{9}$ About 12 percent of the households were classified as non-poor at baseline but were later reclassified as eligible. To avoid arbitrary classifications, we exclude those households from our analysis.

${ }^{10}$ The sample selection cannot be based on the grade during the follow-up period because that grade is potentially affected by the treatment.
} 
The key intuition is that, after conditioning for the number of neighboring evaluation localities, the parceling of those assigned to the treatment and control groups is random. This enables us to identify the effect on schooling decisions of the variations in treatment frequency induced by the randomized evaluation within any neighborhood of an evaluation village.

Neighborhoods are defined as concentric circles around each evaluation village using geodesic distance $d$ as the radius. ${ }^{11}$ Program treatment $T_{j}$ is administered at the village level. It is randomly assigned only within the subset of 506 villages which participated in the evaluation of the program, and not all beneficiary villages participated in the evaluation. Hence, as described in subsection 2.3, neighborhoods of evaluation villages are comprised of other evaluation villages, non-evaluation beneficiary villages, and non-eligible villages. Let then $N_{j, d, t}^{B}=N_{j, d, t}^{T}+N_{j, d, t}^{N E}$ denote the total number of program beneficiary villages situated within distance $d$ from evaluation village $j$ in a given post-treatment period $t$. Among those, $N_{j, d, t}^{T}$ is the number of evaluation villages which are randomly assigned to the treatment group of the evaluation and $N_{j, d, t}^{N E}$ is the number of other neighboring (nonevaluation) villages which are targeted by the intervention during each post-treatment period t. Now let $N_{j, d, t}^{P}=N_{j, d, t}^{T}+N_{j, d, t}^{C}+N_{j, d, t}^{N E}$ denote the number of potential program villages situated at distance $d$ from village $j$ in a given post-treatment period $t$, where we have added $N_{j, d, t}^{C}$, to indicate the number of villages randomly assigned to the control group of the evaluation.

To estimate the spillover effect of the program on school participation, we use the following linear regression model:

$$
Y_{i, j, t}=\alpha_{1} T_{j}+\alpha_{2} N_{j, d, t}^{B}+\alpha_{3} N_{j, d, t}^{P}+\alpha_{4}^{\prime} X_{i, j, d}+\epsilon_{i, j, d, t}
$$

where $Y_{i, j, t}$ is a dummy indicating that program-eligible child $i$ in evaluation village $j$ in a given post-treatment period $t$ is going to school, $T_{j}$ is the randomly assigned treatment indicator which denotes whether or not locality $j$ receives the program, $X_{i, j, d}$ is a column-vector of baseline characteristics at the individual, household, village and neighborhood levels, while $\epsilon_{i, j, d, t}$ captures other unobservable determinants of the school participation decision which are potentially correlated with the targeting of the program.

In this framework, the parameter $\alpha_{1}$ captures the sum of the average direct effect of

\footnotetext{
${ }^{11}$ Due to data limitation, we do not take into account the local geography (natural obstacles or communication axes such as mountains, rivers, or valleys) or transportation networks. This restriction may potentially introduce some measurement error in neighborhood characteristics and generate some attenuation biases in our estimates.
} 
program eligibility and the average indirect effects which stem from treatment of other households in the same village. Due to the fact that program treatment status varies at the village level, it is not possible to separately identify these two effects. ${ }^{12}$ The main parameter of interest is $\alpha_{2}$, which captures the neighborhood-level spillovers stemming from the allocation of treatment among the evaluation localities. Finally, the parameter $\alpha_{3}$ captures the effects of any unobserved determinant of the school participation decision that are correlated with the program geographic targeting.

The identification challenge is that more marginalized regions tend to have higher treatment densities (see Table 1) due to a variety of unobserved factors associated with the geographic roll-out of the intervention, which are also likely to affect program outcomes. However, the random program assignment within the subset of evaluation villages provides some exogenous variation in the local density of treatment in the geographic areas surrounding the evaluation villages, over and above the (endogenous) spillover effects coming from the non-evaluation beneficiary villages. After conditioning for the potential treatment frequency in the neighborhood $N_{j, d, t}^{P}$, cross-neighborhood variations in the frequency of the program are solely determined by the random allocation of neighboring evaluation villages to the treatment and control groups. Indeed, the number of program beneficiary villages in the neighborhood is given by the difference between the number of potential beneficiary (or targeted) villages and the number of villages selected into the control group for the randomized evaluation: $N_{i, j, t}^{B}=N_{i, j, t}^{P}-N_{i, j, t}^{C}$. Hence, because the number of villages allocated to the control (and treatment) group is random, the potential schooling outcomes of child $i$ who reside in time $t$ in village $j$ with program treatment status $T_{j}=0,1$ and neighborhood treatment frequency $N_{d, t}^{B}$, are independent of that realized treatment frequency, when controlling for targeted neighborhood treatment frequency $N_{d, t}^{P}$. Formally:

$$
E\left[y_{i, j, t}^{T, N^{B}} \mid N_{j, d, t}^{B}, N_{j, d, t}^{P}\right]=E\left[y_{i, j, t}^{T, N^{B}} \mid N_{j, d, t}^{P}\right]
$$

Under this conditional independence property, comparisons of average outcomes across different levels of actual treatment frequency $N_{i, j, t}^{B}$, e.g. $n_{1}^{B}$ and $n_{2}^{B}>n_{1}^{B}$, at a given level of potential treatment frequency $N_{i, j, t}^{P}$, capture the causal effect of an increase in actual

\footnotetext{
${ }^{12} \mathrm{~A}$ partial population approach, exploiting the presence of ineligible households in beneficiary villages, can be followed, as it has been in previous studies. However, it requires some assumptions, notably that spillovers affect both eligible and ineligible individuals, and is thus not well-suited for investigating spillovers on the take-up of program components.
} 
treatment frequency from $n_{1}^{B}$ to $n_{2}^{B}$. Formally (and omitting the indexes):

$$
\begin{aligned}
E\left[y^{n_{2}^{B}} \mid N^{B}=n_{2}^{B}, N^{P}\right]-E\left[y^{n_{1}^{B}} \mid N^{B}=n_{1}^{B}, N^{P}\right] & =E\left[y^{n_{2}^{B}} \mid N^{B}=n_{2}^{B}, N^{P}\right]-E\left[y^{n_{1}^{B}} \mid N^{B}=n_{2}^{B}, N^{P}\right] \\
& =E\left[y^{n_{2}^{B}} \mid N^{P}\right]-E\left[y^{n_{1}^{B}} \mid N^{P}\right] .
\end{aligned}
$$

As a validation test of the property depicted in equation (2), we use data from the baseline collected in October 1997 on children's school participation, as well as the full set of covariates that we employ in the empirical analysis, and estimate equation (1) using those baseline characteristics as outcomes. This amounts to a test of the balancing of baseline covariates with respect to the variation in local treatment frequency generated by the randomized experiment. Table 2 reports the means and standard deviations for those variables (columns 1-2), along with the associated OLS coefficients of the neighborhood treatment density term $\left(N_{j, d, t}^{B}\right)$. In column 3 , we display the unconditional marginal effects which reveal the presence of systematic differences in observable characteristics across neighborhoods with different degrees of program frequency. Consistent with the targeting design of the program, treatment frequency correlates positively both with the level of deprivation in the centroid village and with the density of villages/population in the neighborhood. However, as reported in column 4, those differences disappear once we control for the potential treatment frequency in the neighborhood $\left(N_{j, t}^{P}\right)$. An F-test of joint significance of all baseline characteristics does not reject the null hypothesis that the entire set of variables is equal to zero ( $\mathrm{p}$-value $=0.227$ ) with this specification. ${ }^{13}$

Our econometric model is thus a linear regression in which we are interested in the parameter of a regressor, the density of actual program villages $N_{j, d, t}^{B}$, which is exogenous once controlling for another regressor - the density of potential program villages $N_{j, d, t}^{P}$ (note that $T_{j}$ is exogenous with or without any conditioning variable). As program targeting is partly correlated with local poverty levels, we expect the estimated parameter of $N_{j, d, t}^{P}$ to be biased downward. However, the bias on that parameter is orthogonal to both the $T_{j}$ and $N_{j, d, t}^{B}$ terms, and hence it does not contaminate the estimates of the $\alpha_{1}$ and $\alpha_{2}$ parameters. ${ }^{14}$

Furthermore, in equation (1), neighborhood treatment frequency is orthogonal to villagelevel program treatment assignment so that the spillover effect of the program can be identified for both treatment and control group villages. This feature of our empirical framework

\footnotetext{
${ }^{13}$ Two of the baseline variables (the share of eligible households and the number of secondary schools) remain marginally statistically associated (at the 10 percent confidence level) with the density of the program. Consistent with our main estimates, we estimate those placebo regressions by using a $5 \mathrm{~km}$ radius $(d=5)$. Results (available upon request) are very similar when considering alternative radiuses.

${ }^{14}$ This statement is formally verified in Section B of the supplemental appendix.
} 
allows us to disentangle whether spatial externalities extend to the entire population or exclusively affect the outcomes of children and families who are included in the program. We thus consider the following variant of equation (1):

$$
Y_{i, j, t}=\beta_{1} T_{j}+\beta_{2} N_{j, d, t}^{B}+\beta_{3}\left[T_{j} \times N_{j, d, t}^{B}\right]+\beta_{4} N_{j, d, t}^{p}+\beta_{5}\left[T_{j} \times N_{j, d, t}^{P}\right]+X_{i, j, d, t_{0}} \beta_{6}+u_{i, j, d, t}
$$

where the village-level treatment assignment term $\left(T_{j}\right)$ interacts with the density of both actual $\left(N_{j, d, t}^{B}\right)$ and potential $\left(N_{j, d, t}^{P}\right)$ neighboring beneficiary localities so that the effects of cross-village externalities are identified separately for the control and treatment groups. This specification allows us to test whether or not program externalities differentially vary with treatment assignment $\left(\beta_{3} \neq 0\right)$.

To be more explicit on the parameter we estimate, note that our model is equivalent to one in which we are interested in the effects of the neighboring evaluation villages assigned to the treatment group, $N_{i, j, t}^{T}$, and we condition for the numbers of evaluation villages, $N_{i, j, t}^{E}$, and non-evaluation beneficiary villages, $N_{i, j, t}^{N E}$. This model writes:

$$
Y_{i, j, t}=\alpha_{1} T_{j}+\alpha_{2} N_{j, d, t}^{T}+\alpha_{3} N_{j, d, t}^{E}+\alpha_{4} N_{j, d, t}^{N E}+\alpha_{5}^{\prime} X_{i, j, d}+\epsilon_{i, j, d, t} .
$$

The same conditional independence property that stems from the randomized allocation into treatment of neighboring evaluation localities implies that $N_{i, j, t}^{T}$ is random conditional on $N_{j, d, t}^{E}$ and $N_{j, d, t}^{N E}$, that is:

$$
E\left[y_{i, j, t}^{T, N^{T}} \mid N_{j, d, t}^{T}, N_{j, d, t}^{E}, N_{j, d, t}^{N E}\right]=E\left[y_{i, j, t}^{T, N^{T}} \mid N_{j, d, t}^{E}, N_{j, d, t}^{N E}\right]
$$

The $\alpha_{2}$ parameter in equations (1) and (4) capture the effects of the same exogenous variation in neighborhood treatment density (that is the spillover effect of the experimental treatment group villages) and the estimates obtained with these two models are the same.

In addition, we do not assume that the effects of spillovers are linear. We can account for non-linearities by using discrete variables indicating the specific numbers of neighboring treatment villages, and use a flexible (or 'granular') specification for the numbers of evaluation or non-evaluation localities in the neighborhood. Below (see Section 3.2), we report the estimates of equation (1) with one single parameter for the number of beneficiary villages, as well as those of equation (4) with fully discretized controls for the numbers of experimental treatment, evaluation and non-evaluation beneficiary localities. ${ }^{15}$ While the former

\footnotetext{
${ }^{15}$ Given the small number of experimental treatment localities within the neighborhoods in our sample (see Table 1), we group them into two binary categorical variables according to the presence of one or two
} 
provides an average spillover effect, the later specification allows us to check for the presence of non-linearities in the marginal effects of neighboring evaluation localities assigned to treatment.

Finally, several other features of the empirical specifications depicted above should be noted. First, the parameter $\alpha_{2}$ in equation (1) is estimated out of the subset of eligible households of the controlled experiment that have other evaluation villages in the neighborhood of radius $d$. For a radius of $5 \mathrm{~km}$, we have such identifying variation for 42 percent of the evaluation villages.

Second, the inclusion of the vector of socio-demographic variables $X_{i, j, d}$ in equations (1), (3) and (4) is meant to increase the precision of the estimates. The control variables are all measured at baseline using the 1997 data in order to avoid any endogeneity concern, and taking advantage of the panel dimension of the data, include, in particular, baseline school enrollment. The remaining control variables are as follows: child's gender and age (both in levels and squares); parental education; distance to the nearest city; the share of eligible households; the presence of a secondary school in the locality; total population in the locality; the number of localities; total population; and the mean degree of marginalization in the neighborhood. We also include state and year fixed effects.

Lastly, in order to account for the fact that evaluation villages may belong to multiple neighborhoods, we cluster standard errors for groups of partially overlapping neighborhoods. These groups are defined as sets of evaluation villages such that each village lies within the radius-based neighborhood of another village of the set. Intuitively, as soon as an evaluation village belongs to two radius-based neighborhoods, those two neighborhoods will belong to the same cluster. This allows for correlations beyond single radiuses. In the empirical analysis, our preferred specification uses a $5 \mathrm{~km}$ radius but we also use concentric radiuses of 10 and $20 \mathrm{~km}$. Considering a larger radius leads to a smaller number of clusters. In particular, the 506 villages in the experiment belong to 358 clusters of partially overlapping 5 km neighborhoods - the 320 treatment villages belong to 249 such clusters - and this number reduces to 180 when considering clusters formed by overlapping $10 \mathrm{~km}$ neighborhoods, and 45 with $20 \mathrm{~km}$ ones.

\subsection{Main results}

Tables 3 and 4 report the OLS estimates of the spillover effects of the program on eligible children's school participation decisions. The estimates are obtained using the data for the or more such localities (vis-a-vis zero) in the neighborhood. 
post-treatment period (October 1998 and November 1999).

The estimates in Table 3 correspond to the model in equation (1) with continuous variables for the numbers of beneficiary, $N^{B}$, and potential beneficiaries, $N^{P}$. The estimates are obtained with two alternative measures of program frequency $N^{B}$ in the areas surrounding the evaluation villages: the models in columns 1-3 use the numbers of villages treated in a $5 \mathrm{~km}$ radius, while those in columns 4-6 instead use the numbers of eligible households within the same radius. This second definition takes into account the variations in population density across neighborhoods, and hence possibly better captures the extent of potential interactions among program beneficiaries. We report and discuss only the estimates of the parameters $\alpha_{1}$ and $\alpha_{2}$ but, as explained above, the regressions further include controls for the numbers of potential beneficiaries, and for baseline characteristics observed in October 1997, notably baseline school enrollment. ${ }^{16}$

Column 1 of Table 3 reports the estimates for the baseline model in equation (1) when measuring program frequency by the numbers of villages. It indicates that when considering the entire sample of children in treatment and control villages, while living in a treated community increases school participation by 9.7 percent, having an additional treated village within a $5 \mathrm{~km}$ radius further increases enrollment rates by 2.9 percent (this spillover effect is statistically significant at the 10 percent level). The estimated own-village treatment effect of the program is in line with the results obtained in previous studies (e.g., Schultz (2004)).

In order to document the heterogeneity of cross-village externalities by treatment status, column 2 of Table 3 reports OLS estimates of the augmented model specified in equation (3) and column 3 estimates of the model in equation (1) obtained after restricting the sample to the treatment group. ${ }^{17}$ Program externalities appear to matter only for children who live in treatment group localities. Column 2 indeed shows no evidence of spillovers affecting school enrollment of children in control villages (the parameter for the main effect of program frequency has a negative point estimate and it is not statistically significant), but it does show evidence of strong spillovers for the treatment group. The point estimate for the differential effect of spillovers in treatment villages as compared to control villages (given by the parameter for the interaction term $\beta_{3}$ in equation 3) reaches 7.8 percent, and this estimated differential effect is statistically significant at the 5 percent level. ${ }^{18}$ The finding of

\footnotetext{
${ }^{16}$ The last rows of Table 3 report the estimated coefficients of the conditioning term $N^{P}$ in equation (2), split into its two components, $N^{E}$ and $N^{N E}$. Those are, in general, negative and significant, suggesting the presence of strong downward biases stemming from the process of geographic targeting of evaluation villages and non-evaluation villages.

${ }^{17} \mathrm{We}$ also ran probit estimates of the same models and obtained very similar estimates of the effects of spillovers - the results are available upon request.

${ }^{18}$ Note that when we allow for heterogenous effects of program spillovers, the relative OLS coefficient of
} 
spillovers restricted to the control group is confirmed by the estimates reported in column 3 , in which we restrict the sample to the treatment group. The effect on school enrollment of having an additional treated village within a $5 \mathrm{~km}$ radius is estimated at 5.6 percent, and it is statistically significant at the 1 percent level. The specifications reported in columns 4-6 of Table 3 which use the numbers of households, normalized by 100, for measuring program frequency in the areas surrounding the evaluation villages give very similar results to the corresponding ones in columns 1-3.

Table 4 reports the estimates for the model in equation (4); the effects of program frequency are captured directly by the number of treatment group villages $N^{T}$, which, as discussed above, is the source of variation in local treatment frequency that serves to identify spillovers in all our specifications. We use two indicator variables that indicate the presence of one or two or more treatment group villages in the neighborhood. These estimates also incorporate fully discrete controls for the numbers evaluation and non-evaluation beneficiary villages. We report and discuss the estimates of the parameters $\alpha_{1}, \alpha_{2}$, but also of $\alpha_{3}$ for the main conditioning variable, which is the number of evaluation localities in the neighborhood. The regressions further include indicator variables for each non-evaluation beneficiary village and total numbers of villages (we do not report the corresponding parameter estimates, as these numbers can be very large), as well as for baseline characteristics observed in October 1997, notably baseline school enrollment. Figure 2 shows the visual representation of the estimates of the average spillover effects reported in column 1 of Table 4 . They indicate that a treatment group village in the neighborhood increases school participation by 6.1 percent, while two or more neighboring treatment group villages increase it by 8.0 percent. These estimates show that spatial spillovers do not increase linearly with the number of treated villages in the neighborhood. The point estimates reported in column 2 for the differential effect of spillovers in treatment villages as compared to control villages are larger in magnitude, but reveal a similar pattern. ${ }^{19}$

the village-level treatment assignment term $\left(\beta_{1}\right)$ decreases only slightly (to 8.1 percent). We argue that this is due to the simultaneous presence of non-evaluation treated neighboring villages together with the fact that program spillovers accrue exclusively between beneficiaries. With this view, the estimated own-village effect of the program on school enrollment would also embed a portion of the program spillovers stemming from the non-evaluation treated neighbors.

${ }^{19}$ This non-linear shape of the spillover effects with respect to the frequency of nearby program beneficiaries can be related to a broad class of models of discrete decisions with strategic complementarities, and/or the presence of threshold effects in the spillover function - see, e.g., Brock \& Durlauf (2001), Glaeser \& Scheinkman (2000). These cross-villages effects are of the same magnitude or slightly higher than the ones that have been documented for the effects of program spillovers within-villages (from beneficiaries to non-beneficiaries) in the same setting, that is around 5 percent (Bobonis \& Finan 2009, Lalive \& Cattaneo 2009). 


\subsection{Further evidence}

To investigate whether spillovers operate over relatively short or larger distances, Table 5 reports the OLS estimates of the model in equation (1) using measures of program frequency in neighborhoods covering larger distances over and above those of program frequency in the 0-5 $\mathrm{km}$ radius. As in Table 3, we use the number of villages (columns 1-4) and eligible households (columns 5-8) as two alternative measures of program frequency. Columns 1 and 5 use the same baseline specification as columns 1 and 4 of Table 3 with the entire sample. Columns 2 and 6 use the restricted sample of children in treated villages (as do columns 3 and 6 of Table 3). For the estimates in columns 3, 4, 7 and 8, we measure program frequency over a $20 \mathrm{~km}$ radius and weight the observations in each village by the inverse of the distance to the centroid.

The estimated coefficients for the numbers of treated villages located at a distance between 5 and $10 \mathrm{~km}$ are small and statistically insignificant, whereas the corresponding estimates at a distance between 0 and $5 \mathrm{~km}$ barely change with respect to those presented in Table 3. This suggests the presence of a strong decay rate in spatial externalities. However, the specifications using the distance-weighted density measures computed over the 20 $\mathrm{km}$ radius confirm the presence of positive spillovers on school participation in treatment group localities. Overall, these results indicate that spillovers operate over relatively short

distances. Since we find no evidence of spillovers of beneficiaries over larger distances, in the rest of the analysis we focus on those operating over 0 to $5 \mathrm{~km}$.

As a robustness check, we consider an alternative specification that instruments the actual treatment frequency in the neighborhood with the randomized treatment frequency. However, if we control for both the number of evaluation localities and non-evaluation beneficiary localities, the first stage becomes evidently mechanical with an additional treatment locality increasing by one the number of beneficiary localities in the neighborhood. In order to avoid such a mechanical first-stage relationship, we remove from the specification the variable corresponding to the number of non-evaluation program villages $\left(N^{N E}\right)$. Note that we still have to control for the number of neighboring evaluation villages $\left(N^{E}\right)$ in order to account for the fact that the identifying variation is non-zero for 42 percent of the evaluation villages (i.e. those that have at least another evaluation village in their radius $0-5 \mathrm{~km}$ ), and in order to assure that the exclusion restriction is valid (because of the correlation across village neighborhoods between $N^{E}$ and $N^{N E}$ ).

The corresponding estimation results are reported in Table 6 . The point estimate of the first-stage parameter for the effect of an additional treatment group village on neighborhood 
treatment density is estimated at 1.43 (column 1). The corresponding t-statistic is 1.97 and the $\mathrm{F}$ test of the excluded instrument is 3.9 , which is statistically significant at the 5 percent level. The reduced form coefficient for the effect of the number of treated villages in the 0-5 km radius on secondary school enrollment is 0.028 (column 2), which is very much in line with the corresponding estimate reported in column 1 of Table 3 . Column 3 reports the IV estimate of the relationship between the frequency of neighboring program localities and secondary school enrollment, which is positive but not significantly different from zero. The IV point estimate has a smaller magnitude than the OLS one reported in column 2, which reflects the larger-than-one first-stage relationship, and is estimated with more noise due to the reduced statistical power in this specification.

As a last robustness exercise, we consider alternative measures of program take-up based on the health component of the program. We use household-level information from the postprogram survey round of October 1998 on the uptake of three screening tests that form part of the health requirements of the Progresa program: hypertension (blood pressure test), diabetes (blood sugar test) and cervical cancer (via the PAP smear test). ${ }^{20}$ Table 7 reports the OLS estimates of both own-village treatment effects and the spatial spillover effects stemming from neighboring program villages on the probability that the households in the sample comply with the health conditionality of the program. The estimates reveal the presence of a strong effect of the program on the probability that eligible households comply with its health requirements, as confirmed by the positive and large marginal effects associated with the variable indicating whether or not the own village of residence of the households in the sample received the program. ${ }^{21}$ The estimated coefficients of cross-village externalities are reported in columns 1,3 and 5 of Table 7 . These are also positive but not significantly different from zero - with the exception of the specification using the uptake of the blood sugar test as dependent variable (column 3), which features an estimated externalities coefficient that is significant at the 10 percent level.

We next estimate the heterogenous effect model reported in equation (3). The corresponding estimates are reported in columns 2, 4 and 6 of Table 7. Externalities coefficients

\footnotetext{
${ }^{20}$ The household respondents were asked whether or not any household member had been screened for these conditions in the previous six months. In order to maintain full comparability with the estimates of program spillover reported in the paper, we estimate at the household-level the linear model reported in equation (1) in the paper on the same sample that we consider in the main empirical analysis. Results (available upon request) are very similar in both magnitude and precision, if we instead consider the larger sample of all program-eligible households in October 1998.

${ }^{21}$ As we note in Section 3.1, the fact that program treatment status varies at the village level implies that such estimates capture both the direct effect of the program as well as the average indirect effects which stem from the treatment of other individuals in the same village.
} 
for households residing in treated villages are more precisely estimated and larger in magnitude when compared to their average counterparts (except for the PAP smear test), whereas those for control villages cannot be distinguished from zero. An additional neighboring program village increases compliance with health screening by roughly 10 percent for households who reside in a program village, or about half of the "own-village" treatment effect and a 2030 percent increase vis-a-vis the corresponding mean in the control group. These estimates of health spillovers are broadly consistent with those of the enrollment spillovers reported in Table 3, both in terms of incidence (they accrue exclusively among program participants) and of the magnitude. They are slightly more imprecise though, possibly due to the smaller sample size resulting from household-level regressions and one year of program follow-up data.

\section{Mechanisms}

We now use additional information gathered from both program operational surveys and administrative sources in order to shed some light on the interpretation behind the patterns uncovered in Section 3. The finding of spillovers on school enrollment operating over short distances supports a simple model of peer effects on program take-up decisions of eligible households. ${ }^{22}$ As we do not have measures of the occurrences of interactions of beneficiaries from different neighboring villages, we cannot report direct evidence of this. Hence, we conduct several indirect checks for the presence of such interactions. On the other hand, some spatial variations in the local implementation of the program could also a priori explain the observed relationship between the local density of the treatment and program impacts. We thus also test for the presence of such spatial variations in the implementation of the intervention under study.

\subsection{Knowledge spillovers among program participants}

In spite of the emphasis placed on informing the potential participants about the objectives, design and requirements of the intervention, concerns have been expressed by those involved in the initial phases of the implementation regarding the effectiveness of the diffusion of information about the program among targeted households (Adato et al. 2000). To further

\footnotetext{
${ }^{22}$ Non-market interactions may affect take-up decisions through two channels: information and social norms. While conceptually different, these two forms of social behaviors can hardly be distinguished empirically. We thus broadly refer to the influence of others on individual responses as peer effects.
} 
corroborate this anecdotal evidence, we use information from an operational follow-up survey conducted among eligible households in the evaluation treatment-group villages in May 1999 (i.e., 14 months after the inception of the program). Program beneficiaries were asked to identify three sets of benefits distributed by Progresa: (i) scholarships and school supplies, (ii) food stipends and nutritional supplements, and (iii) preventive health care and health check-ups. Most of the respondents who were to receive the transfers were mothers. While 98 percent of the respondents were able to spontaneously and correctly mention the nutrition component, only 60 percent correctly identified both the health and education components. Knowledge of the program components was thus incomplete in treatment villages at that time.

In such a context of sparse and coarse knowledge about the benefits of the intervention, information-sharing among potential beneficiaries is likely to have played a role, notably among the women who are the primary recipients of the transfers and regularly encounter each other during program operations. When asked, in the same operational follow-up survey, to mention the most significant changes within their communities, half of the beneficiaries reported that the program had increased the degree of cooperation among women.

For further evidence on this, we estimate the effects of spatial spillovers on those measures of eligible households' knowledge of the different program components. Table 5 reports the estimates, which are obtained using the model in equation (1) estimated at the household-level using the October 1998 data. Having one additional neighboring program village increases by 4.5 and 8.2 percent respectively, the share of eligible households that are aware of the education and health components (columns 1 and 2), and has a smaller and no significant effect on the share of households aware of the nutritional component (column 3).

Given the evidence of program externalities on school participation decisions presented in Section 3, the observed variations of the knowledge of the education component could reflect increases in school attendance rather than the presence of peer effect among potential beneficiaries. Yet, the take-up patterns of the program discussed in Section 2.2 make it difficult to interpret the evidence of the knowledge indicators of other program components (such as health benefits), as purely stemming from corresponding variations in school enrollment among program-eligible children.

\subsection{Supply-side effects}

Areas with higher densities of program participants may have benefited from more efficient program operations, or from improvements in the supply of education or health services, 
thereby helping some eligible households to comply with the schooling requirements of the program. A related alternative explanation is that the implementation of the program may have been more efficient when the number of evaluation treatment group villages in the neighborhood (rather than the total number of beneficiaries) was higher. While both notions of implementation scale gains seem a priori reasonable, we argue that they are unlikely to explain our results.

To examine the presence of differences in implementation and supply, two preliminary points should be noted. First, any variation in program delivery in a given geographic area should evenly benefit those program recipients who reside within it. This is at odds with the evidence reported in column 1 of Table 5, that program spillovers appear spatially concentrated within relatively small areas surrounding the evaluation villages. According to this line of thought, school supply-side changes would likely affect the enrollment decisions of both recipients and non-recipients, an idea difficult to reconcile with the evidence of heterogeneous externalities reported in column 2 of Table 3.

Second, we identify spatial spillovers using only the variation in program frequency generated by the randomized experiment. This variation is small compared to the overall scale of the program (as seen in Table 1, in a given $5 \mathrm{~km}$ radius, there are on average 10 beneficiary villages but only 0.6 evaluation villages, among which 0.4 are assigned to the treatment group and 0.2 to the control group). Program frequency is thus not much different in neighborhoods that have more treatment-group villages compared to those that have more control-group villages, and the resulting infra-marginal changes in the scale of the program are unlikely to trigger any supply-side efficiency gain.

We next run a battery of complementary tests aimed at detecting the presence of supplyside responses associated with experimental variations in the frequency of the treatment in the areas surrounding evaluation villages. We begin with two measures of implementation efficiency at the village-level. According to qualitative interviews with beneficiaries, local program staff, school teachers and health staff (see Adato et al. 2000), one major source of inefficiency in program delivery was the delays in the delivery of the form for school attendance monitoring (E1 form), and the associated delays in the payment of scholarships. First, we use program administrative data on the monetary transfers (for scholarships and school supplies) delivered to eligible households to compute the number of months from incorporation until the first disbursements were made to the beneficiary households in treated villages. $^{23}$ Second, we use information from the operational follow-up survey in order to

\footnotetext{
${ }^{23}$ While food stipends were distributed to all villages assigned to the treatment group at the same time in March 1998, only 56 percent of the those localities received the first scholarship transfer in March 1998; 36
} 
construct the share of program recipients in treated villages that received the E1 form as of May 1999.

In order to maintain full comparability with the estimates of program spillover reported in the rest of the paper, we estimate at the village-level the linear model reported in equation (1), using those program implementation measures as dependent variables on the sample of treated villages that we consider in the main empirical analysis. ${ }^{24}$ The dependent variables are time-invariant, and hence we match this information with only the first round (1998) of the data of the program roll-out. As documented in columns 1-3 of Table 9, these three measures of efficiency of program implementation are unrelated to the frequency of the treatment in the areas surrounding evaluation villages.

We next use the yearly secondary school census in order to construct school supply aggregate measures for the 358 evaluation neighborhoods in our sample (with both treated and control villages as centroid), and estimate at the neighborhood-level the linear model reported in equation (1) over the two years of the program roll-out (1998-1999). In all specifications, we control for the baseline (1997) value of the dependent variable. The OLS estimates are reported in panel B of Table 9, which are very small in magnitude and not statistically different from zero.

\section{Conclusion}

We examined, in the context of the Progresa-Oportunidades conditional cash transfer program, whether or not the take-up of the schooling component of the program is influenced by the presence of other beneficiaries in areas comprising several villages. We found evidence of positive spillovers within networks of beneficiaries spanning those areas. A higher local frequency of program beneficiaries increases the take-up of the scholarships for secondary schooling offered by the program and, accordingly, school enrollment at that level. In contrast, these effects do not affect the schooling decisions of households in the control group villages that were not yet incorporated into the program.

percent received them two months later, and the remaining 8 percent six months or more after incorporation into the program. These administrative delays appear concentrated in some regions, notably in the states of Queretaro and San Luis Potosi. As a further check, we have re-estimated equation (1) without those two states. Results (available upon request) are very similar to those reported in Table 3

${ }^{24}$ Results (available upon request) barely change when we consider instead the entire sample of 320 treated villages. Due to a few missing values in the additional data sources that we employ, we lose some village-level observations in the regressions displayed in panel A of Table 2: three villages for scholarship disbursements, four villages for school supply disbursements and seven villages for the receipt of the school attendance (E1) form. 
To better understand our findings, we tested and found suggestive evidence for the presence of knowledge spillovers among program-eligible households. While we could not directly test for the presence of social interactions, we found that higher treatment densities in the neighborhoods were associated with increased knowledge among eligible households of the schooling and health components of the program. We also tested the alternative hypothesis that the spillover effect that we estimate instead reflects heterogeneities in direct treatment impacts due to spatial variations in the implementation of the program. The evidence we obtained is not consistent with this interpretation of our findings.

Spillover effects on program take-up have implications for the design and implementation of social policies in developing countries. The magnitude of the estimated effect suggests that there can be large gains from the spatial concentration of the target population of an intervention, as local networks of potential beneficiaries can act as social multipliers in the take-up of the proposed benefits. Spillover effects also have implications for the evaluation of social policy interventions, notably in settings where a program is implemented over an extended area and treatment frequency is high. In particular, capturing those effects across villages, so as to recover impact evaluation parameters that incorporate spillovers, requires the analysis of the impacts of the program at the level of relatively large geographical areas or clusters. The feasibility of this option critically hinges upon the scale of the program that is being evaluated, and statistical power reasons may push the researcher to opt for a narrower definition of the evaluation clusters. These considerations can be particularly important for policy interventions that are evaluated at scale, a setting which likely differs from the evaluation of small pilot programs.

\section{References}

Adato, M., Coady, D. \& Ruel, M. (2000), An operations evaluation of progresa from the perspective of beneficiaries, promotoras, school directors, and health staff, Technical report, International Food Policy Research Institute.

Aizer, A. \& Currie, J. (2004), 'Networks or neighborhoods? correlations in the use of publicly-funded maternity care in california', Journal of Public Economics 88(12), 25732585 .

Akerlof, G. A. (1997), 'Social distance and social decisions', Econometrica 65(5), 1005-1028.

Angelucci, M. \& De Giorgi, G. (2009), 'Indirect effects of an aid program: How do cash transfers affect ineligibles' consumption?', American Economic Review 99(1), 486-508.

Angelucci, M., De Giorgi, G., Rangel, M. A. \& Rasul, I. (2010), 'Family networks and school enrollment: Evidence from a randomized social experiment', Journal of Public Economics 94(3-4), 197-221. 
Angelucci, M., De Giorgi, G. \& Rasul, I. (2012), Resource sharing within family networks: insurance and investment.

Baird, S., Bohren, J. A., McIntosh, C. \& Ozler, B. (2014), Designing Experiments to Measure Spillover Effects, PIER Working Paper Archive 14-006, Penn Institute for Economic Research, Department of Economics, University of Pennsylvania.

URL: https://ideas.repec.org/p/pen/papers/14-006.html

Banerjee, A., Duflo, E., Glennerster, R. \& Dhruva, K. (2010), 'Improving immunization coverage in rural india: A clustered randomized controlled evaluation of immunization campaigns with and without incentives', BMJ 340.

Bertrand, M., Luttmer, E. F. P. \& Mullainathan, S. (2000), 'Network effects and welfare cultures', The Quarterly Journal of Economics 115(3), 1019-1055.

Bobonis, G. J. \& Finan, F. (2009), 'Neighborhood peer effects in secondary school enrollment decisions', Review of Economics and Statistics 91(4), 695-716.

Brock, W. A. \& Durlauf, S. N. (2001), 'Discrete Choice with Social Interactions', Review of Economic Studies 68(2), 235-260.

Crepon, B., Duflo, E., Gurgand, M., Rathelot, R. \& Zamora, P. (2013), 'Do labor market policies have displacement effects? evidence from a clustered randomized experiment', The Quarterly Journal of Economics 128(2), 531-580.

Daponte, B. O., Sanders, S. \& Taylor, L. (1999), 'Why do low-income households not use food stamps? evidence from an experiment', Journal of Human Resources 34(3), 612-628.

Duflo, E. \& Saez, E. (2003), 'The role of information and social interactions in retirement plan decisions: Evidence from a randomized experiment', The Quarterly Journal of Economics 118(3), 815-842.

Fiszbein, A. \& Schady, N. (2009), Conditional Cash Transfers. Reducing Present and Future Poverty, The World Bank, Washington DC.

Glaeser, E. L. \& Scheinkman, J. (2000), Non-Market Interactions, NBER Working Papers 8053, National Bureau of Economic Research, Inc.

URL: https://ideas.repec.org/p/nbr/nberwo/8053.html

Glewwe, P. \& Kremer, M. (2006), Schools, teachers, and education outcomes in developing countries, Vol. 2 of Handbook of the Economics of Education, Elsevier, chapter 16, pp. 9451017.

Ichino, N. \& Schundeln, M. (2012), 'Deterring or displacing electoral irregularities? spillover effects of observers in a randomized field experiment in ghana', The Journal of Politics 74, 292-307.

Kuhn, P., Kooreman, P., Soetevent, A. \& Kapteyn, A. (2011), 'The effects of lottery prizes on winners and their neighbors: Evidence from the dutch postcode lottery', American Economic Review 101(5), 2226-47.

Lalive, R. \& Cattaneo, M. A. (2009), 'Social interactions and schooling decisions', The Review of Economics and Statistics 91(3), 457-477.

Miguel, E. \& Kremer, M. (2004), 'Worms: Identifying impacts on education and health in the presence of treatment externalities', Econometrica 72(1), 159-217. 
Moffitt, R. A. (2001), Policy Interventions, Low Level Equilibria, and Social Interactions, MIT Press, pp. 45-82.

Parker, S. W., Rubalcava, L. \& Teruel, G. (2008), Evaluating Conditional Schooling and Health Programs, Vol. 4 of Handbook of Development Economics, Elsevier, chapter 62, pp. 3963-4035.

Schultz, T. (2004), 'School subsidies for the poor: Evaluating the mexican progresa poverty program', Journal of Development Economics 74(1), 199-250. 


\section{Figures and Tables}

Figure 1: Program Coverage (1998-1999)

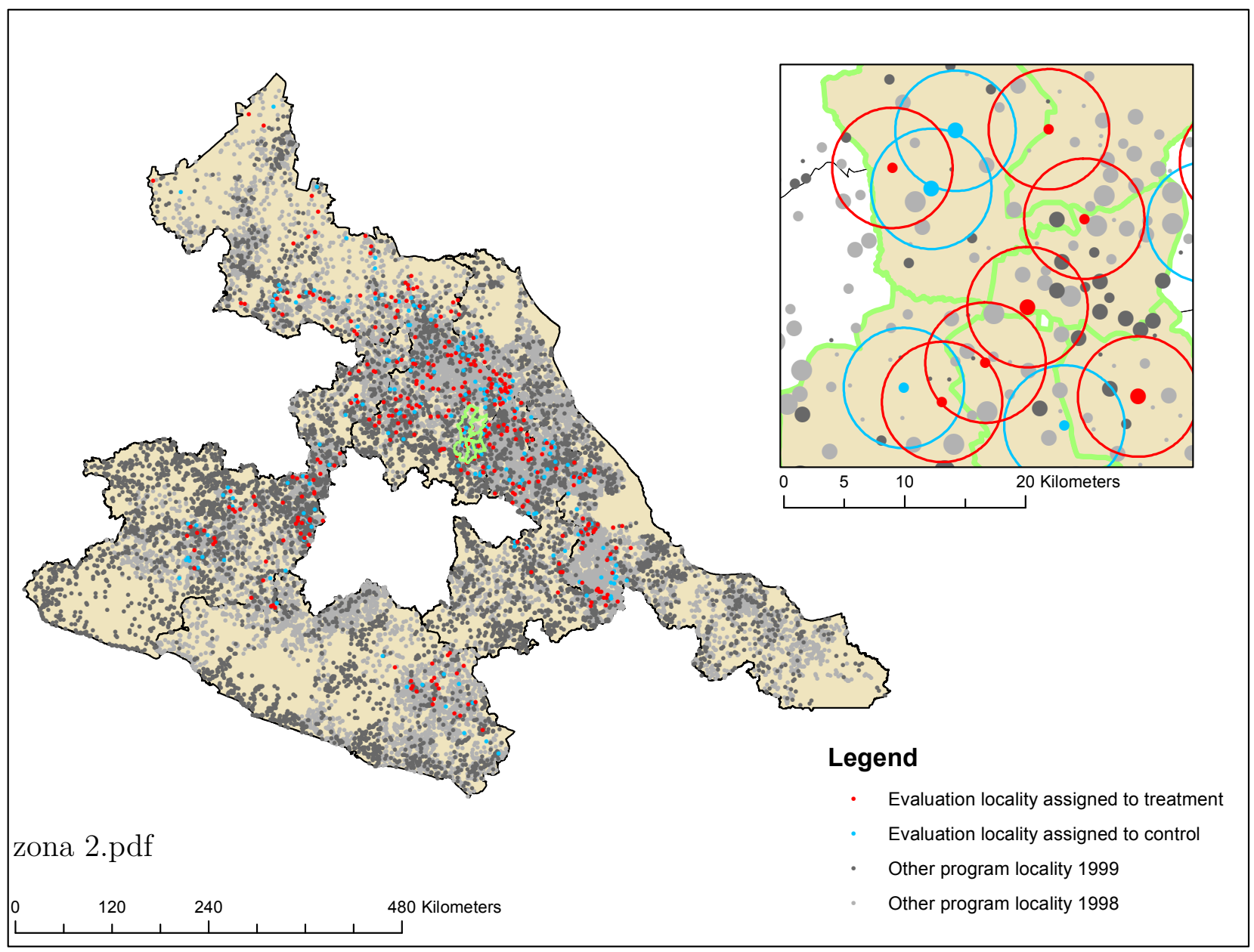

Note: This figure reports the geographic locations of the villages targeted by the program during the period 1998-1999 in the seven central states of Mexico in which the evaluation of the program took place. The quadrant in the upper right hand corner displays a close-up view of a region in the state of Michoacan in which the size of the markers has been adjusted for the relative population size, and $5 \mathrm{~km}$ radiuses are displayed around each evaluation village. 
Figure 2: Marginal Spillover Effects - Granular Specification

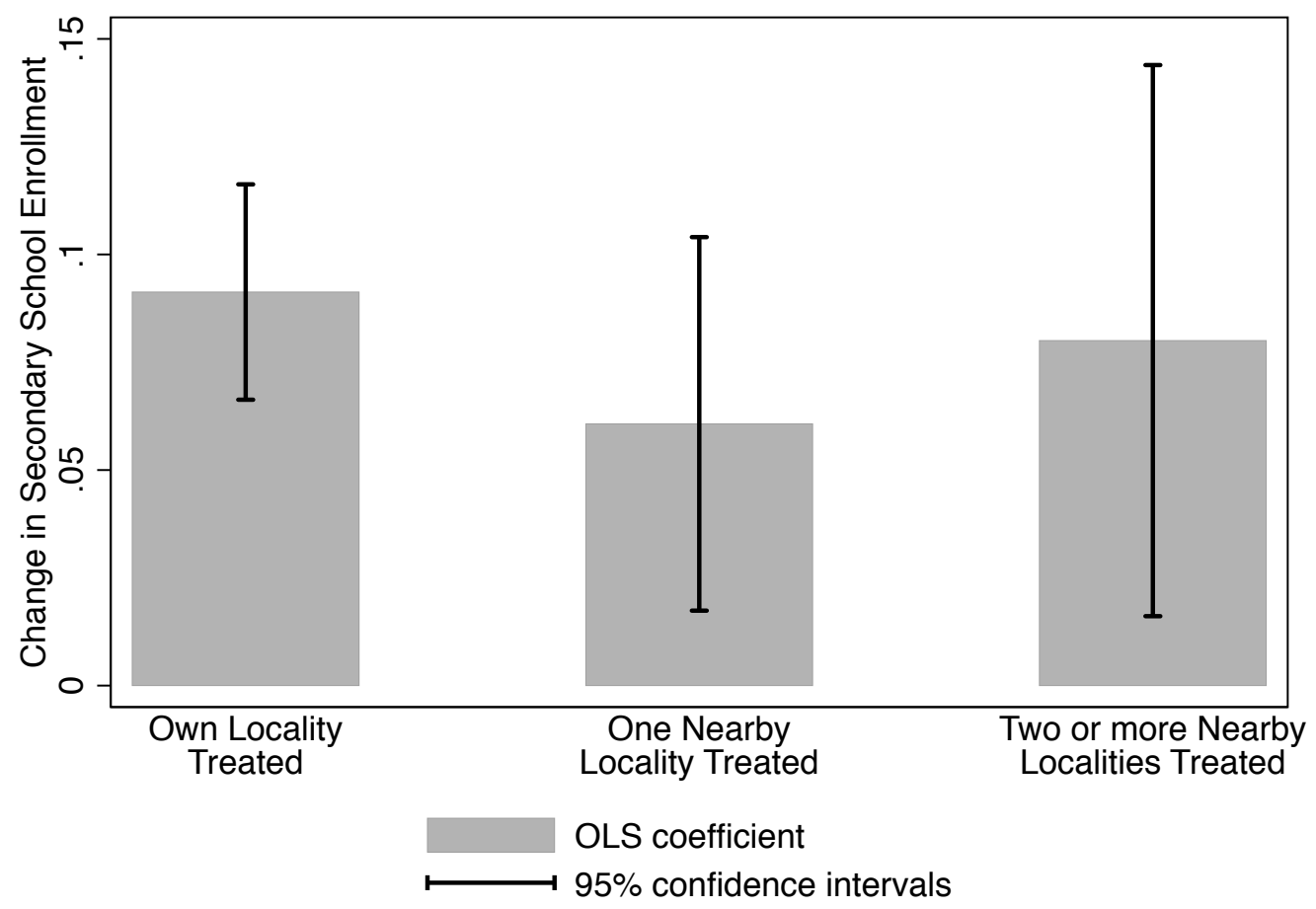

NotE: This figure depicts the OLS coefficients and the associated 95 percent confidence intervals on school participation decisions of the own village treatment term, along with those for the indicator variables for having one and two or more neighboring treated villages, respectively. The full set of estimated coefficients of equation (4) is reported in Table 4. The sample contains program-eligible children in evaluation villages, observed in October 1998 and November 1999, who, at baseline, are aged less than 18 and have completed grades 5 or 6 of primary school and the first grade of secondary school. Standard errors are clustered at the level of groupings of partially overlapping neighborhoods. All specifications control for baseline school enrollment. 
Table 1: Treatment Frequency in Neighborhood Around Evaluation Villages

\begin{tabular}{ccccccc}
\hline \hline \multirow{3}{*}{ Sample } & & \multicolumn{3}{c}{ Neighborhood Poverty } & \multicolumn{2}{c}{ Treat Assignment } \\
& All & Low & High & & Treat & Control \\
& $(1)$ & $(2)$ & $(3)$ & & $(4)$ & $(5)$ \\
\hline
\end{tabular}

Numbers of beneficiaries in neighborhood

$\begin{array}{lccccc}\text { \# Beneficiary villages } & 10.0 & 6.66 & 13.3 & 10.2 & 9.64 \\ & (8.13) & (5.07) & (9.19) & (8.20) & (8.04) \\ \text { \# Children in beneficiary villages } & 834 & 565 & 1104 & 831 & 841 \\ & (864) & (641) & (968) & (839) & (908) \\ \text { \# Scholarship recipients } & 386 & 252 & 520 & 385 & 386 \\ & (402) & (283) & (455) & (385) & (430)\end{array}$

Distribution of evaluation villages in neighborhood

$\begin{array}{lccccc}\text { \# Evaluation villages } & 0.62 & 0.44 & 0.80 & 0.63 & 0.61 \\ & (0.92) & (0.68) & (1.08) & (0.94) & (0.87) \\ \text { Prob(1 evaluation village) } & 0.27 & 0.24 & 0.31 & 0.28 & 0.26 \\ & (0.45) & (0.43) & (0.46) & (0.45) & (0.44) \\ \text { Prob(2 evaluation villages) } & 0.11 & 0.09 & 0.13 & 0.11 & 0.12 \\ & (0.32) & (0.29) & (0.34) & (0.31) & (0.33) \\ \text { Prob(3+ evaluation villages) } & 0.03 & 0.01 & 0.06 & 0.03 & 0.03 \\ & (0.17) & (0.06) & (0.24) & (0.17) & (0.18)\end{array}$

Distribution of evaluation villages assigned to treatment in neighborhood

$\begin{array}{lccccc}\text { \# Treated villages } & 0.40 & 0.27 & 0.53 & 0.40 & 0.39 \\ & (0.71) & (0.52) & (0.84) & (0.74) & (0.65) \\ \text { Prob(1 treated village }) & 0.24 & 0.19 & 0.28 & 0.24 & 0.25 \\ & (0.43) & (0.43) & (0.40) & (0.42) & (0.43) \\ \text { Prob(2+ treated villages }) & 0.07 & 0.04 & 0.09 & 0.07 & 0.06 \\ & (0.25) & (0.19) & (0.29) & (0.25) & (0.25)\end{array}$

Total Villages in Evaluation Sample $\quad 506 \quad 253 \quad 253 \quad 320 \quad 186$

NotE: This table reports means and standard deviations (in parentheses) for the numbers of neighboring beneficiary villages, children (aged 6-14) in those villages and scholarship recipients, and the mean numbers and distribution of neighboring evaluation and treatment group villages within areas delimited by $5 \mathrm{~km}$ radius around evaluation localities. Source: Progresa October 1998 evaluation survey. The sample in column 1 contains all evaluation localities. In columns 2-3, we split the sample of evaluation localities according to the median of the mean index of marginalization in the neighborhood. In columns $4-5$, we split the sample according to the program treatment assignment indicator of the village situated in the centroid of each neighborhood. 
Table 2: Neighborhood Treatment Frequency and Baseline Characteristics

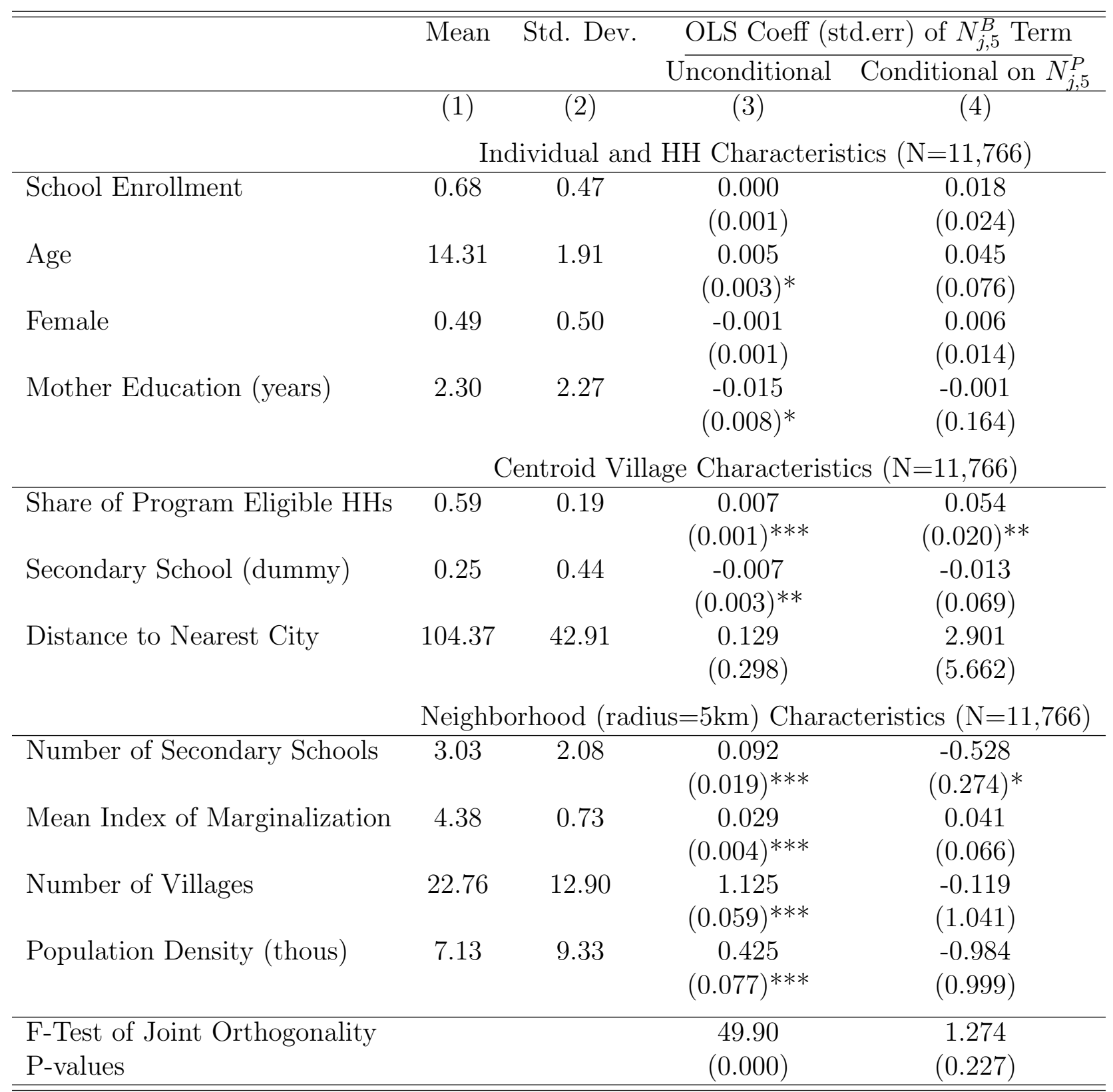

* significant at $10 \% ; * *$ significant at $5 \% ; * * *$ significant at $1 \%$.

Notes: This table reports means and standard deviations (columns 1-2) of the school participation (enrollment) outcome at baseline (October 1997), as well as the full set of covariates we employ in the empirical analysis. In columns 3-4, we display the OLS coefficient of the neighborhood treatment frequency term $\left(N_{j, 5}^{B}\right)$ on each of those baseline characteristics, respectively, without and with its potential counterpart $\left(N_{j, 5}^{P}\right)$ as a conditioning term. Standard errors clustered at the level of groupings of partially overlapping neighborhoods are reported in parenthesis below each OLS coefficients. Source: Progresa 1997 targeting and baseline survey and geo-referenced list of beneficiary localities. The sample contains program-eligible children in evaluation villages, observed in October 1998 and November 1999, who, at baseline, are aged less than 18 and have completed grades 5 or 6 of primary school and the first grade of secondary school. 
Table 3: Spatial Spillovers of the Program on Secondary School Enrollment

\begin{tabular}{|c|c|c|c|c|c|c|}
\hline Own Village Treated & $\begin{array}{c}(1) \\
0.097^{* * *} \\
(0.014)\end{array}$ & $\begin{array}{c}(2) \\
0.081^{* * *} \\
(0.025)\end{array}$ & $(3)$ & $\begin{array}{c}(4) \\
0.095^{* * *} \\
(0.014)\end{array}$ & $\begin{array}{c}(5) \\
0.081^{* * *} \\
(0.023)\end{array}$ & 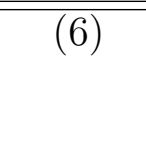 \\
\hline Actual Treatment Frequency & \multicolumn{3}{|c|}{ Villages } & \multicolumn{3}{|c|}{ Eligible households (x100) } \\
\hline \# Treated in $0-5 \mathrm{~km}$ & $\begin{array}{l}0.029^{*} \\
(0.015)\end{array}$ & $\begin{array}{l}-0.020 \\
(0.023)\end{array}$ & $\begin{array}{c}0.056 * * * \\
(0.020)\end{array}$ & $\begin{array}{c}0.039 \\
(0.024)\end{array}$ & $\begin{array}{l}-0.026 \\
(0.042)\end{array}$ & $\begin{array}{c}0.070 * * \\
(0.035)\end{array}$ \\
\hline$(\#$ Treated in $0-5 \mathrm{~km}) \times$ Treat & \multicolumn{3}{|c|}{$\begin{array}{c}0.078^{* *} \\
(0.033)\end{array}$} & \multicolumn{3}{|c|}{$\begin{array}{c}0.10^{*} \\
(0.056)\end{array}$} \\
\hline Potential Treatment Frequency & \multicolumn{3}{|c|}{ Villages } & \multicolumn{3}{|c|}{ Eligible households (x100) } \\
\hline \# Evaluation in $0-5 \mathrm{~km}$ & $\begin{array}{c}-0.020 \\
(0.014)\end{array}$ & $\begin{array}{c}0.013 \\
(0.021)\end{array}$ & $\begin{array}{c}-0.047^{* *} \\
(0.020)\end{array}$ & $\begin{array}{l}-0.017 \\
(0.024)\end{array}$ & $\begin{array}{c}0.038 \\
(0.038)\end{array}$ & $\begin{array}{l}-0.050 \\
(-.037)\end{array}$ \\
\hline (\# Evaluation in $0-5 \mathrm{~km}) \times$ Treat & & $\begin{array}{c}-0.055^{*} \\
(0.030)\end{array}$ & & & $\begin{array}{c}-0.083 \\
(0.056)\end{array}$ & \\
\hline \# Non-Eval in $0-5 \mathrm{~km}$ & $\begin{array}{c}-0.031^{* *} \\
(0.015)\end{array}$ & $\begin{array}{c}0.017 \\
(0.023)\end{array}$ & $\begin{array}{c}-0.058^{* * *} \\
(0.020)\end{array}$ & $\begin{array}{l}-0.039 \\
(0.024)\end{array}$ & $\begin{array}{c}0.026 \\
(0.042)\end{array}$ & $\begin{array}{c}-0.069^{*} \\
(0.035)\end{array}$ \\
\hline$(\#$ Non-Eval in $0-5 \mathrm{~km}) \times$ Treat & & $\begin{array}{c}-0.077^{* *} \\
(0.033)\end{array}$ & & & $\begin{array}{c}-0.097^{*} \\
(0.057)\end{array}$ & \\
\hline Number of Observations & 11766 & 11766 & 7317 & 11766 & 11766 & 7317 \\
\hline R-squared & 0.364 & 0.365 & 0.383 & 0.364 & 0.365 & 0.382 \\
\hline Number of Clusters & 358 & 358 & 249 & 358 & 358 & 249 \\
\hline
\end{tabular}

* significant at $10 \%$; ** significant at $5 \%$; *** significant at $1 \%$.

Notes: This table reports OLS estimates of cross-village program spillovers on school participation decisions following the specifications in equations (1) and (3). The dependent variable equals 1 if the child currently attends school. Columns 1-3 use the numbers of villages treated in a $5 \mathrm{~km}$ radius as a measure of treatment frequency. Columns 4-6 use the corresponding numbers of households over the same radius. Parameters are reported for the number of evaluation and non-evaluation potential beneficiary villages (columns 1-3) and households (columns 4-6) within the radius controls. Other controls include: baseline school enrollment; child's gender; age and age squared; parental education; distance to the nearest city; the share of eligible households; the presence of a secondary school in the locality; total population, the number of secondary schools; the mean degree of marginalization in the radius; state dummies; and a dummy for year 1998. Standard errors are clustered at the level of groupings of partially overlapping neighborhoods are reported in parentheses. Source: Progresa evaluation surveys and geo-referenced census of localities and secondary schools. The sample contains program-eligible children in evaluation villages, observed in October 1998 and November 1999, who, at baseline, are aged less than 18 and have completed grades 5 or 6 of primary school and the first grade of secondary school. It is restricted to treatment villages in columns 3 and 6 . 
Table 4: Granular Model of Spatial Spillovers

\begin{tabular}{lcc}
\hline \hline & $(1)$ & $(2)$ \\
\hline Own village treated & $0.091^{* * *}$ & $0.121^{* * *}$ \\
& $(0.013)$ & $(0.018)$ \\
1 treated village in 0-5km & $0.061^{* * *}$ & -0.016 \\
& $(0.022)$ & $(0.030)$ \\
2 or more treated villages in 0-5km & $0.080^{* *}$ & -0.009 \\
& $(0.033)$ & $(0.044)$ \\
(1 treated village in 0-5km)×Treat & & $0.105^{* *}$ \\
& & $(0.044)$ \\
(2 or more treated villages in 0-5km) $\times$ Treat & & $0.153^{* *}$ \\
& & $(0.065)$ \\
1 evaluation village in 0-5km & $-0.053^{* *}$ & $0.074^{* * *}$ \\
& $(0.023)$ & $(0.028)$ \\
2 evaluation villages in 0-5km & $-0.082^{* *}$ & -0.001 \\
& $(0.032)$ & $(0.037)$ \\
3 evaluation villages in 0-5km & 0.066 & $0.122^{*}$ \\
& $(0.043)$ & $(0.064)$ \\
4 evaluation villages in 0-5km & -0.065 & 0.151 \\
& $(0.111)$ & $(0.111)$ \\
5 evaluation villages in 0-5km & -0.050 & -0.058 \\
6 evaluation villages in 0-5km & $(0.048)$ & $(0.069)$ \\
dummies for \# non-evaluation villages & -0.021 & -0.107 \\
dummies for \# villages dummies & $(0.056)$ & $(0.065)$ \\
Number of Observations & Yes & Yes \\
Number of Clusters & 11766 & Yes \\
\hline \hline
\end{tabular}

* significant at $10 \%$; ${ }^{* *}$ significant at $5 \%$; $* * *$ significant at $1 \%$.

NotES: This table reports OLS estimates of cross-village program spillovers on school participation decisions using a 'granular', or fully discretized, specification of equation (4). The dependent variable equals 1 if the child currently attends school. The measures of treatment are the numbers of evaluation villages allocated to treatment within $5 \mathrm{~km}$ ( 1 or 2 or more), and controls include indicating variables for the fully discretized numbers of evaluation villages, non-evaluation beneficiary villages and total number of villages in a $5 \mathrm{~km}$ radius. Controls are also included for child's school enrollment at baseline, gender, age and age squared, parental education, distance to the nearest city, the share of eligible households and the presence of a secondary school in the locality; total population, the number of localities, the number of secondary schools and the mean degree of marginalization in the radius; state dummies and a dummy for year 1998. Standard errors are clustered at the level of groupings of partially overlapping neighborhoods are reported in parentheses. Source: Progresa evaluation surveys and geo-referenced census of localities and secondary schools. The sample contains program-eligible children in evaluation villages, observed in October 1998 and November 1999, who, at baseline, are aged less than 18 and have completed grades 5 or 6 of primary school and the first grade of secondary school. 
Table 5: Specification Checks

\begin{tabular}{|c|c|c|c|c|c|c|c|c|}
\hline & $(1)$ & $(2)$ & $(3)$ & $(4)$ & $(5)$ & $(6)$ & $(7)$ & $(8)$ \\
\hline Own Village Treated & $\begin{array}{c}0.094^{* * *} \\
(0.016)\end{array}$ & & $\begin{array}{c}0.096^{* * *} \\
(0.009)\end{array}$ & & $\begin{array}{c}0.092^{* * *} \\
(0.015)\end{array}$ & & $\begin{array}{c}0.094^{* * *} \\
(0.010)\end{array}$ & \\
\hline Actual Treatment Frequency & \multicolumn{4}{|c|}{ Villages } & \multicolumn{4}{|c|}{ Eligible households (x100) } \\
\hline \# treated in $0-5 \mathrm{~km}$ & $\begin{array}{c}0.025^{*} \\
(0.015)\end{array}$ & $\begin{array}{c}0.062^{* * *} \\
(0.020)\end{array}$ & & & $\begin{array}{l}0.040^{*} \\
(0.021)\end{array}$ & $\begin{array}{c}0.078^{* *} \\
(0.036)\end{array}$ & & \\
\hline$\#$ treated in $5-10 \mathrm{~km}$ & $\begin{array}{r}-0.0058 \\
(0.016)\end{array}$ & $\begin{array}{c}0.014 \\
(0.015)\end{array}$ & & & $\begin{array}{c}-0.004 \\
(0.019)\end{array}$ & $\begin{array}{c}0.008 \\
(0.020)\end{array}$ & & \\
\hline \# treated distance-weighted & & & $\begin{array}{c}0.029 \\
(0.025)\end{array}$ & $\begin{array}{c}0.087^{* *} \\
(0.042)\end{array}$ & & & $\begin{array}{c}0.032 \\
(0.026)\end{array}$ & $\begin{array}{c}0.110^{* *} \\
(0.043)\end{array}$ \\
\hline Number of Obs & 11766 & 7317 & 11766 & 7317 & 11766 & 7317 & 11766 & 7317 \\
\hline R-squared & 0.364 & 0.384 & 0.365 & 0.381 & 0.365 & 0.384 & 0.365 & 0.380 \\
\hline Number of Clusters & 180 & 137 & 45 & 36 & 180 & 137 & 45 & 36 \\
\hline
\end{tabular}

* significant at $10 \% ; * *$ significant at $5 \% ; * * *$ significant at $1 \%$.

Notes: This table reports OLS estimates of cross-village program spillovers on school participation decisions following the specifications in equations (1) and (3). The dependent variable equals 1 if the child currently attends school. As measures of treatment, columns 1-4 use the numbers of villages treated, respectively within $5 \mathrm{~km}, 10 \mathrm{~km}$, and $20 \mathrm{~km}$ with distance weights, while columns 5-8 use the numbers of eligible households respectively within $5 \mathrm{~km}, 10 \mathrm{~km}$, and $20 \mathrm{~km}$ with distance weights. Standard errors are clustered at the level of groupings of partially overlapping neighborhoods are reported in parentheses. Control variables include: baseline school enrollment; the numbers of potential beneficiary villages (columns 1-4) or eligible households (columns 5-8); child's gender age and age squared; parental education; distance to the nearest city; the share of eligible households; the presence of a secondary school in the locality; total population; the number of localities; the number of secondary schools; the mean degree of marginalization in the radius; state dummies and a dummy for year 1998 . Source: Progresa evaluation surveys and geo-referenced census of localities and secondary schools. The sample contains program-eligible children in evaluation villages, observed in October 1998 and November 1999, who, at baseline, are aged less than 18 and have completed grades 5 or 6 of primary school and the first grade of secondary school. 
Table 6: Spatial Spillovers of Progresa on Secondary School Enrollment: IV Estimates

\begin{tabular}{|c|c|c|c|}
\hline $\begin{array}{l}\text { Dependent Variable } \\
\text { Estimator }\end{array}$ & $\begin{array}{c}\text { Treatment intensity } \\
\text { OLS } \\
(1)\end{array}$ & $\begin{array}{c}\text { School Enrollment } \\
\text { OLS } \\
(2)\end{array}$ & $\begin{array}{c}\text { School Enrollment } \\
\text { 2SLS } \\
(3)\end{array}$ \\
\hline $\begin{array}{l}\text { Randomized Treatment Frequency } \\
(0-5 \mathrm{~km})\end{array}$ & $\begin{array}{l}1.436^{* *} \\
(0.729)\end{array}$ & $\begin{array}{l}0.028^{*} \\
(0.016)\end{array}$ & \\
\hline $\begin{array}{l}\text { Actual Treatment Frequency } \\
(0-5 \mathrm{~km})\end{array}$ & & & $\begin{array}{c}0.019 \\
(0.018)\end{array}$ \\
\hline Own Village Treated & $\begin{array}{l}1.078^{* *} \\
(0.526) \\
\end{array}$ & $\begin{array}{c}0.096^{* * *} \\
(0.014) \\
\end{array}$ & $\begin{array}{c}0.075^{* * *} \\
(0.023)\end{array}$ \\
\hline \multicolumn{4}{|l|}{ Weak identification tests: } \\
\hline $\begin{array}{l}\text { Kleibergen-Paap Wald rk F statistic } \\
\text { Prob }>F(1,79)\end{array}$ & $\begin{array}{c}3.87 \\
0.0498\end{array}$ & & \\
\hline Mean Dependent Variable & 11.807 & 0.582 & \\
\hline Number of Observations & 11766 & 11766 & 11766 \\
\hline R-squared & 0.707 & 0.364 & 0.319 \\
\hline Number of Clusters & 358 & 358 & 358 \\
\hline
\end{tabular}

$*$ significant at $10 \%$;* significant at $5 \%$;** significant at $1 \%$

NotE: This Table reports OLS and 2SLS estimates of cross-village spillovers on school enrollment decisions. The dependent variable equals 1 if the child currently attends school. All specifications include the treatment assignment indicator at the locality-level and the number of evaluation villages in the neighborhood, and baseline school enrollment. The other control variables include: child's gender age and age squared; parental education; distance to the nearest city; the share of eligible households; the presence of a secondary school in the locality; total population, the number of localities, the number of secondary schools; the mean degree of marginalization in the radius; state dummies and a dummy for year 1998. Standard errors clustered at the level of groupings of partially overlapping neighborhoods are reported in parentheses. Source: Progresa evaluation surveys and geo-referenced census of localities and secondary schools. The sample contains program-eligible children in the Progresa evaluation localities with at least another evaluation locality in their close proximity $(5 \mathrm{~km})$, observed in October 1998 and November 1999, who, at baseline, are aged less than 18 and have completed grades 5 or 6 of primary school and the first grade of secondary school. 
Table 7: Spatial Spillovers of Progresa on the Uptake of the Health Screening Tests

\begin{tabular}{|c|c|c|c|c|c|c|}
\hline \multirow{2}{*}{$\begin{array}{l}\text { Chronic Disease } \\
\text { Screening Test }\end{array}$} & \multicolumn{2}{|c|}{$\begin{array}{l}\text { Hypertension } \\
\text { Blood Pressure }\end{array}$} & \multicolumn{2}{|c|}{$\begin{array}{c}\text { Diabetes } \\
\text { Blood Sugar }\end{array}$} & \multicolumn{2}{|c|}{$\begin{array}{l}\text { Cervical Cancer } \\
\text { PAP smear }\end{array}$} \\
\hline & $(1)$ & & $(3)$ & $(4)$ & $(5)$ & $(6)$ \\
\hline Own Village Treated & $\begin{array}{c}0.205^{* * *} \\
(0.021)\end{array}$ & $\begin{array}{c}0.241^{* * *} \\
(0.032)\end{array}$ & $\begin{array}{c}0.162^{* * *} \\
(0.024)\end{array}$ & $\begin{array}{c}0.192^{* * *} \\
(0.039)\end{array}$ & $\begin{array}{c}0.134^{* * *} \\
(0.023)\end{array}$ & $\begin{array}{c}0.204^{* * *} \\
(0.038)\end{array}$ \\
\hline \# Treated Villages in $0-5 \mathrm{~km}$ & $\begin{array}{c}0.039 \\
(0.032)\end{array}$ & $\begin{array}{l}-0.031 \\
(0.042)\end{array}$ & $\begin{array}{l}0.058^{*} \\
(0.032)\end{array}$ & $\begin{array}{l}-0.017 \\
(0.043)\end{array}$ & $\begin{array}{c}0.033 \\
(0.031)\end{array}$ & $\begin{array}{c}0.008 \\
(0.027)\end{array}$ \\
\hline \# Treated Villages in $0-5 \mathrm{~km} \times$ Treat & & $\begin{array}{c}0.114^{* *} \\
(0.053)\end{array}$ & & $\begin{array}{c}0.123^{* *} \\
(0.056)\end{array}$ & & $\begin{array}{c}0.044 \\
(0.046)\end{array}$ \\
\hline Mean of Dep. Var. in Control Group & & & & & & \\
\hline Number of Observations & 4522 & 4522 & 4523 & 4523 & 4522 & 4522 \\
\hline R-squared & 0.102 & 0.108 & 0.073 & 0.078 & 0.091 & 0.094 \\
\hline Number of Clusters & 358 & 358 & 358 & 358 & 358 & 358 \\
\hline
\end{tabular}

* significant at $10 \%$; ** significant at $5 \%$; *** significant at $1 \%$.

NotE: This Table reports OLS estimates of cross-village spillovers on the likelihood of compliance with three screening tests that form part to the health requirements of the Progresa program following the specification in equation (1). The dependent variables equals 1 if at least one household member reports having being screened in the previous six months for the corresponding chronic condition. Standard errors clustered at the level of groupings of partially overlapping neighborhoods are reported in parentheses. All specifications control for baseline school enrollment. The other control variables include: the potential number of beneficiary villages; parental education; distance to the nearest city; the share of eligible households; the presence of a secondary school in the locality; total population, the number of localities; the number of secondary schools; the mean degree of marginalization in the radius, and state dummies. Source: Progresa evaluation surveys and geo-referenced census of localities and secondary schools. The sample contains program-eligible households residing in Progresa evaluation villages observed in October 1998 whose children, at baseline, are aged less than 18 and have completed grades 5 or 6 of primary school and the first grade of secondary school. 
Table 8: Knowledge About the Program Components

\begin{tabular}{lccc}
\hline \hline & $\begin{array}{c}\text { Scholarship } \\
(1)\end{array}$ & $\begin{array}{c}\text { Health } \\
(2)\end{array}$ & $\begin{array}{c}\text { Nutrition } \\
(3)\end{array}$ \\
\hline \multirow{3}{*}{ \# Treated Villages 0-5km } & $\begin{array}{c}0.045^{* *} \\
(0.022)\end{array}$ & $\begin{array}{c}0.082^{* * *} \\
(0.029)\end{array}$ & $\begin{array}{c}0.011 \\
(0.007)\end{array}$ \\
\hline Baseline enrollment & Yes & Yes & Yes \\
Other controls & Yes & Yes & Yes \\
State Dummies & Yes & Yes & Yes \\
Number of Obs & 3858 & 3858 & 3858 \\
R-squared & 0.073 & 0.053 & 0.026 \\
Number of Clusters & 242 & 242 & 242 \\
\hline \hline
\end{tabular}

* significant at $10 \%$; ** significant at $5 \%$; ** significant at $1 \%$.

Notes: This table reports OLS estimates of cross-village externalities on dichotomous indicators of whether or not recipients know the various components of the benefits package of the program following the specification in equation (1). Standard errors clustered at the level of groupings of partially overlapping neighborhoods are reported in parentheses. The following baseline control variables are included in each specification: the potential number of beneficiary villages within $5 \mathrm{~km}$; child's gender age and age squared; parental education; distance to the nearest city; the share of eligible households; the presence of a secondary school in the locality; total population; the number of localities; the number of secondary schools; the mean degree of marginalization in the radius; state dummies and a dummy for year 1998. Source: Progresa evaluation surveys, geo-referenced census of localities and secondary schools, and Progresa follow-up survey of recipients. The sample contains program-eligible households residing in treated villages observed in October 1998 whose children, at baseline, are aged less than 18 and have completed grades 5 or 6 of primary school and the first grade of secondary school. 
Table 9: Supply-Side Responses

\begin{tabular}{|c|c|c|c|}
\hline \multicolumn{4}{|c|}{ Panel A: Indicators of Efficiency of Program Delivery at the Village Level (centroid) } \\
\hline \multirow[t]{2}{*}{ Dependent Variable } & \multicolumn{2}{|c|}{ Months of Delays in Monetary Transfers } & \multirow{2}{*}{$\begin{array}{l}\text { Share of HHs who } \\
\text { Received of E1 Form } \\
(3)\end{array}$} \\
\hline & $\begin{array}{c}\text { Scholarships } \\
(1)\end{array}$ & $\begin{array}{c}\text { School Supplies } \\
\text { (2) }\end{array}$ & \\
\hline \# Villages treated in $0-5 \mathrm{~km}$ & $\begin{array}{l}-0.007 \\
(0.140)\end{array}$ & $\begin{array}{l}-0.043 \\
(0.132)\end{array}$ & $\begin{array}{c}0.001 \\
(0.024)\end{array}$ \\
\hline Village controls & Yes & Yes & Yes \\
\hline Neighborhood controls & Yes & Yes & Yes \\
\hline State Dummies & Yes & Yes & Yes \\
\hline Mean of Dep. Var. & 1.1 & 6.4 & .56 \\
\hline Number of Observations & 306 & 305 & 302 \\
\hline R-squared & 0.343 & 0.111 & 0.080 \\
\hline Number of Clusters & 247 & 246 & 243 \\
\hline \multicolumn{4}{|c|}{ Panel B: Aggregate School Characteristics at the Neighborhood Level $(0-5 \mathrm{~km})$} \\
\hline & $\begin{array}{l}\text { Number of } \\
\text { Schools } \\
(1)\end{array}$ & $\begin{array}{l}\text { Number of } \\
\text { Teachers } \\
(2)\end{array}$ & $\begin{array}{c}\text { Share of } \\
\text { High Ed. Teachers } \\
(3)\end{array}$ \\
\hline \# Villages treated in $0-5 \mathrm{~km}$ & $\begin{array}{c}0.045 \\
(0.080)\end{array}$ & $\begin{array}{l}-1.121 \\
(0.767)\end{array}$ & $\begin{array}{l}-0.030 \\
(0.022)\end{array}$ \\
\hline Baseline Value of Dep. Var. & Yes & Yes & Yes \\
\hline Neighborhood Controls & Yes & Yes & Yes \\
\hline Year Dummy (1998) & Yes & Yes & Yes \\
\hline State Dummies & Yes & Yes & Yes \\
\hline Mean of Dep. Var. & 3 & 15 & .2 \\
\hline Number of Observations & 716 & 716 & 716 \\
\hline R-squared & 0.953 & 0.968 & 0.589 \\
\hline Number of Clusters & 358 & 358 & 358 \\
\hline
\end{tabular}

* significant at $10 \% ; * *$ significant at $5 \% ; * * *$ significant at $1 \%$.

Notes: This table reports OLS estimates of the effects of local treatment frequency on measures of the program's supply-side. Standard errors clustered at the level of groupings of partially overlapping neighborhoods are reported in parentheses. Source: geo-referenced census of localities and secondary schools, and Progresa follow-up survey of recipients. The treated villages observed in 1998 are in Panel A and the evaluation neighborhoods observed in both 1998 and 1999 are in Panel B. 


\title{
Neighborhood Effects in Integrated Social Policies
}

\author{
Matteo Bobba* Jérémie Gignoux ${ }^{\dagger}$ \\ Web Appendix - Not for Publication
}

\section{A Randomness of the Evaluation Sample}

We hereby provide the english translation for a few extracts of an official document from the original evaluation of the program (Progresa, 1997), which clearly suggest that the evaluation sample was indeed selected randomly among the set of the program eligible localities in the seven Mexican States in which the program was initially implemented.

[...]The evaluation sample (cf. BASAL y CONTROL) is constituted of rural (i.e. 50-4,999 inhabitants) and marginalized (i.e. high or very high values of an underlying proxy-mean poverty score) localities with access to primary and secondary schools that are located in Progresa catchment areas in the States of Guerrero, Hidalgo, Michoacán, Puebla, Querétaro, San Luis Potosí and Veracruz. [...]The sample was randomly drawn from the population of those program eligible localities scheduled to be incorporated in 1997, after stratification by geographic region (which roughly coincide with States) and population size.

In the regression analysis discussed in the paper, individual school participation decisions after the program takes place (1998-1999) are affected by the local frequency of program incorporated villages over the same period in the areas surroundings their villages of residence. Hence, beyond the presumed randomness of the evaluation sample vis-a-vis the villages that were incorporated during the baseline of the program evaluation (1997), we are also interested in assessing the extent to which the evaluation villages are similar to those that were incorporated in the program during the subsequent phases of the roll-out of the intervention in rural areas. Basic socio-demographic variables extracted from the 2000 Mexican population census indicate that localities that are lately incorporated into the program are on average larger and less marginalized (see Panel A of Table A.1). However, the differences in means between incorporation phases are largely attenuated once we restrict the sample to those localities that are situated in $5 \mathrm{~km}$ neighborhoods (as defined in the paper) of the evaluation localities (see panel B of Table A.1).

\footnotetext{
*Toulouse School of Economics, University of Toulouse Capitole, 21 Allée de Brienne 31000 Toulouse France. E-mail: matteo.bobba@tse-fr.eu.

${ }^{\dagger}$ Paris School of Economics (INRA), 48 boulevard Jourdan 75014 Paris France. E-mail: gignoux@pse.ens.fr.
} 
Table A.1: Socio-Demographics Characteristics and the Phase of Program Incorporation

\begin{tabular}{|c|c|c|c|c|c|c|}
\hline \multirow[t]{2}{*}{ Year } & \multicolumn{2}{|c|}{1997} & \multicolumn{2}{|c|}{1998} & \multicolumn{2}{|c|}{1999} \\
\hline & $\begin{array}{l}\text { Mean } \\
(1)\end{array}$ & $\begin{array}{c}\text { Std. Dev. } \\
(2)\end{array}$ & $\begin{array}{c}\text { Mean } \\
(3)\end{array}$ & $\begin{array}{c}\text { Std. Dev. } \\
\text { (4) }\end{array}$ & $\begin{array}{c}\text { Mean } \\
(5)\end{array}$ & $\begin{array}{c}\text { Std. Dev. } \\
(6)\end{array}$ \\
\hline \multicolumn{7}{|c|}{ Panel A: All Localities in the Seven States in which the Program Evaluation Took Place } \\
\hline Size size & \multicolumn{2}{|c|}{$\mathrm{N}=2,249$} & \multicolumn{2}{|c|}{$\mathrm{N}=11,987$} & \multicolumn{2}{|c|}{$\mathrm{N}=6,124$} \\
\hline Poverty mean-score & 0.63 & 0.65 & 0.61 & 0.69 & 0.09 & 0.88 \\
\hline $\mathrm{Nb}$ of Households & 70.17 & 94.71 & 73.74 & 99.91 & 91.35 & 171.17 \\
\hline Population $($ age $\leq 5)$ & 59.58 & 83.63 & 63.99 & 88.98 & 71.93 & 141.81 \\
\hline Population $(6 \leq$ age $<15)$ & 91.47 & 124.62 & 96.64 & 129.09 & 108.20 & 204.99 \\
\hline Population (age $\geq 15$ ) & 202.9 & 280.1 & 207.5 & 279.6 & 258.1 & 489.5 \\
\hline Presence of secondary school & 0.20 & 0.40 & 0.19 & 0.40 & 0.22 & 0.42 \\
\hline$\%$ Literate $($ age $\geq 15)$ & 0.69 & 0.13 & 0.70 & 0.14 & 0.75 & 0.14 \\
\hline$\%$ Children in School $(6 \leq$ age $<15)$ & 0.90 & 0.09 & 0.88 & 0.10 & 0.87 & 0.12 \\
\hline Altitude (meters above see level) & 940.2 & 683.2 & 1092.7 & 855.6 & 1238.5 & 886.6 \\
\hline \% Population in Workforce & 0.43 & 0.11 & 0.40 & 0.13 & 0.39 & 0.13 \\
\hline \multicolumn{7}{|c|}{ Panel B: Only Localities in a 5-km Neighborhood of the Evaluation Sample } \\
\hline Size size & \multicolumn{2}{|c|}{$\mathrm{N}=717$} & \multicolumn{2}{|c|}{$\mathrm{N}=3,048$} & \multicolumn{2}{|c|}{$\mathrm{N}=829$} \\
\hline Poverty mean-score & 0.66 & 0.64 & 0.67 & 0.72 & 0.16 & 0.99 \\
\hline $\mathrm{Nb}$ of Households & 68.32 & 87.73 & 63.67 & 74.21 & 76.63 & 200.37 \\
\hline Population $($ age $\leq 5)$ & 57.78 & 78.32 & 55.83 & 68.24 & 60.02 & 149.05 \\
\hline Population $(6 \leq$ age $<15)$ & 90.12 & 117.9 & 84.27 & 97.85 & 91.07 & 214.4 \\
\hline Population (age $\geq 15$ ) & 198.3 & 261.4 & 180.9 & 211.1 & 216.0 & 568.6 \\
\hline Presence of secondary school & 0.19 & 0.40 & 0.17 & 0.37 & 0.20 & 0.40 \\
\hline$\%$ Literate $($ age $\geq 15)$ & 0.68 & 0.13 & 0.68 & 0.15 & 0.72 & 0.17 \\
\hline$\%$ Children in School $(6 \leq$ age $<15)$ & 0.90 & 0.10 & 0.88 & 0.10 & 0.88 & 0.13 \\
\hline Altitude (meters above see-level) & 900.1 & 682.8 & 1215.9 & 842.9 & 1448.8 & 833.4 \\
\hline \% Population in Workforce & 0.44 & 0.12 & 0.42 & 0.14 & 0.42 & 0.14 \\
\hline
\end{tabular}

Note: Both Samples of Panel A and Panel B include the 320 evaluation localities that were randomly assigned to the treatment group.

Table A.2 provides a direct comparison between evaluation localities and the non-evaluation program beneficiary localities in the seven Mexican States from which the evaluation sample was drawn and over the period 1997-1999 (see columns 1 and 2). Column 3 reports the t-statistics of the test of no differences in locality characteristics after controlling for population strata and State fixed effects (as well as a joint F-test) and finds the presence of some unbalances in a few socio-demographic characteristics. In Column 4 we further restrict the comparison within the neighboring localities of each evaluation cluster and do not find evidence of any significant difference between the two samples.

To wrap up, in spite of the random assignment of evaluation villages in 1997, there may be some unbalancedness between the evaluation sample and the non-evaluation sample 
of Progresa localities after 1997. However, those seem to be minor within the relatively homogenous group of neighboring villages that are incorporated in the program over the period 1998-1999 that we consider in our empirical analysis.

Table A.2: Comparison of Means between Evaluation and Non-Evaluation Progresa Localities

\begin{tabular}{|c|c|c|c|c|}
\hline Sample size & $\begin{array}{c}\text { Evaluation } \\
\mathrm{N}=506 \\
(1)\end{array}$ & $\begin{array}{c}\text { Non-Evaluation } \\
\mathrm{N}=20,045 \\
(2)\end{array}$ & $\begin{array}{c}\text { T-test of } \mathrm{P} \\
\mathrm{N}=20,551 \\
(3)\end{array}$ & $\begin{array}{c}\text { Difference } \\
\mathrm{N}=4,785 \\
(4)\end{array}$ \\
\hline Poverty mean-score & $\begin{array}{c}0.47 \\
(0.73)\end{array}$ & $\begin{array}{c}0.46 \\
(0.79)\end{array}$ & $\begin{array}{c}0.002 \\
{[0.971]}\end{array}$ & $\begin{array}{l}-0.039 \\
{[0.112]}\end{array}$ \\
\hline Number of Households & $\begin{array}{c}52.18 \\
(35.20)\end{array}$ & $\begin{array}{c}79.09 \\
(126.4)\end{array}$ & $\begin{array}{c}1.875 \\
{[0.382]}\end{array}$ & $\begin{array}{c}1.758 \\
{[0.164]}\end{array}$ \\
\hline Population (age $\leq 5)$ & $\begin{array}{c}43.61 \\
(34.89)\end{array}$ & $\begin{array}{c}66.27 \\
(107.9)\end{array}$ & $\begin{array}{c}2.459 \\
{[0.079]}\end{array}$ & $\begin{array}{c}2.332 \\
{[0.063]}\end{array}$ \\
\hline Population $(6 \leq$ age $<15)$ & $\begin{array}{c}66.81 \\
(51.70)\end{array}$ & $\begin{array}{l}100.10 \\
(156.6)\end{array}$ & $\begin{array}{c}3.333 \\
{[0.057]}\end{array}$ & $\begin{array}{c}2.086 \\
{[0.217]}\end{array}$ \\
\hline Population (age $\geq 15$ ) & $\begin{array}{l}147.78 \\
(101.8)\end{array}$ & $\begin{array}{l}223.49 \\
(359.3)\end{array}$ & $\begin{array}{c}4.963 \\
{[0.347]}\end{array}$ & $\begin{array}{c}5.090 \\
{[0.142]}\end{array}$ \\
\hline Presence of Secondary School & $\begin{array}{c}0.17 \\
(0.38)\end{array}$ & $\begin{array}{c}0.20 \\
(0.40)\end{array}$ & $\begin{array}{c}0.024 \\
{[0.453]}\end{array}$ & $\begin{array}{c}0.011 \\
{[0.516]}\end{array}$ \\
\hline$\%$ Literate (age $\geq 15$ ) & $\begin{array}{c}0.71 \\
(0.14)\end{array}$ & $\begin{array}{c}0.71 \\
(0.14)\end{array}$ & $\begin{array}{l}-0.013 \\
{[0.221]}\end{array}$ & $\begin{array}{c}0.005 \\
{[0.263]}\end{array}$ \\
\hline$\%$ Children in School $(6 \leq$ age $<15)$ & $\begin{array}{c}0.88 \\
(0.10)\end{array}$ & $\begin{array}{c}0.88 \\
(0.11)\end{array}$ & $\begin{array}{l}-0.003 \\
{[0.666]}\end{array}$ & $\begin{array}{l}-0.002 \\
{[0.612]}\end{array}$ \\
\hline Altitude (meters above see level) & $\begin{array}{c}1273.63 \\
(839.7)\end{array}$ & $\begin{array}{c}1116.90 \\
(852.9)\end{array}$ & $\begin{array}{c}132.739 \\
{[0.060]}\end{array}$ & $\begin{array}{l}11.998 \\
{[0.153]}\end{array}$ \\
\hline \% Population in Workforce & $\begin{array}{c}0.40 \\
(0.13)\end{array}$ & $\begin{array}{c}0.40 \\
(0.13)\end{array}$ & $\begin{array}{l}-0.002 \\
{[0.792]}\end{array}$ & $\begin{array}{c}0.001 \\
{[0.796]}\end{array}$ \\
\hline \multicolumn{3}{|l|}{$\begin{array}{l}\text { F Test of Joint Orthogonality } \\
\text { [p-values] }\end{array}$} & $\begin{array}{c}4.375 \\
{[0.048]}\end{array}$ & $\begin{array}{c}1.045 \\
{[0.404]}\end{array}$ \\
\hline
\end{tabular}

NotE: Columns 1-2 report means and standard deviations (in parenthesis). Columns 3-4 display the OLS coefficients with State fixed effect (Column 3) and Neighborhood fixed effects (Column 4) of the evaluation dummy along with the p-values (in brackets) for the null hypothesis of no difference between evaluation and non-evaluation program localities. Population strata are included in both specifications. Standard errors are clustered at the state level in Column 3 and at the neighborhood level in Column 4.

Turning now to the sample used in the empirical analysis; a direct implication of the presumed randomness of the evaluation sample is that we should expect no differences in the survey characteristics measured in the pre-program year (1997) between evaluation neigh- 
borhoods with a different number of non-centroid evaluation villages after netting out the independent effect of the local frequency of neighboring non-evaluation localities. A simple comparison of means between evaluation neighborhoods with and without non-centroid evaluation villages is shown in columns 1 and 2 of Table A.3. Column 3 reports the effects of the number of evaluation villages after controlling for the number of non-evaluation villages in the neighborhood. Overall, the local frequency of evaluation localities in the neighborhoods of the 506 localities that form part to the Progresa evaluation sample does not seem to be correlated with pre-program observable characteristics at the individual, locality and neighborhood-level. This confirms that the set of evaluation localities is a random subsample of beneficiary localities incorporated after late 1997. 
Table A.3: Baseline Characteristics within the Evaluation Localities

\begin{tabular}{|c|c|c|c|}
\hline Neighborhood & $\begin{array}{c}\text { No Evaluation } \\
\text { Localities } \\
(1)\end{array}$ & $\begin{array}{c}\text { Some Evaluation } \\
\text { Localities } \\
(2)\end{array}$ & $\begin{array}{c}\text { OLS Coefficient of } \\
\text { Number of Eval }\left(N_{j, 5}^{E}\right) \\
(3)\end{array}$ \\
\hline School Enrollment & $\begin{array}{c}0.64 \\
(0.48)\end{array}$ & $\begin{array}{c}0.64 \\
(0.48)\end{array}$ & $\begin{array}{c}0.004 \\
{[0.647]}\end{array}$ \\
\hline \multicolumn{4}{|c|}{ Individual and HH Characteristics } \\
\hline Age & $\begin{array}{l}14.52 \\
(2.02)\end{array}$ & $\begin{array}{l}14.53 \\
(2.06)\end{array}$ & $\begin{array}{l}-0.016 \\
{[0.513]}\end{array}$ \\
\hline Female (dummy) & $\begin{array}{c}0.50 \\
(0.50)\end{array}$ & $\begin{array}{c}0.51 \\
(0.50)\end{array}$ & $\begin{array}{c}0.002 \\
{[0.729]}\end{array}$ \\
\hline Mother Education (years) & $\begin{array}{c}2.36 \\
(2.33)\end{array}$ & $\begin{array}{c}2.36 \\
(2.35)\end{array}$ & $\begin{array}{c}0.077 \\
{[0.396]}\end{array}$ \\
\hline Father Education (years) & $\begin{array}{c}2.20 \\
(2.21)\end{array}$ & $\begin{array}{c}2.25 \\
(2.30)\end{array}$ & $\begin{array}{c}0.085 \\
{[0.139]}\end{array}$ \\
\hline \multicolumn{4}{|c|}{ Centroid Village Characteristics } \\
\hline Share of Program Eligible $\mathrm{HHs}$ & $\begin{array}{c}0.58 \\
(0.20)\end{array}$ & $\begin{array}{c}0.60 \\
(0.19)\end{array}$ & $\begin{array}{l}-0.008 \\
{[0.409]}\end{array}$ \\
\hline Presence of Secondary School & $\begin{array}{c}0.26 \\
(0.44)\end{array}$ & $\begin{array}{c}0.24 \\
(0.43)\end{array}$ & $\begin{array}{l}-0.006 \\
{[0.789]}\end{array}$ \\
\hline Distance to Nearest City (Km) & $\begin{array}{c}106.4 \\
(40.45)\end{array}$ & $\begin{array}{c}102.9 \\
(45.59)\end{array}$ & $\begin{array}{c}4.191 \\
{[0.255]}\end{array}$ \\
\hline \multicolumn{4}{|c|}{ Neighborhood (radius $=5 \mathrm{~km}$ ) Characteristics } \\
\hline Number of Secondary Schools & $\begin{array}{c}2.88 \\
(2.19)\end{array}$ & $\begin{array}{c}3.19 \\
(1.91)\end{array}$ & $\begin{array}{c}0.037 \\
{[0.800]}\end{array}$ \\
\hline Poverty mean-score & $\begin{array}{c}0.41 \\
(0.56)\end{array}$ & $\begin{array}{c}0.57 \\
(0.54)\end{array}$ & $\begin{array}{c}0.042 \\
{[0.151]}\end{array}$ \\
\hline Number of Localities (any) & $\begin{array}{c}21.03 \\
(14.00)\end{array}$ & $\begin{array}{c}25.15 \\
(11.21)\end{array}$ & $\begin{array}{l}-0.181 \\
{[0.798]}\end{array}$ \\
\hline Population density & $\begin{array}{c}5.99 \\
(6.54) \\
\end{array}$ & $\begin{array}{c}8.41 \\
(11.44)\end{array}$ & $\begin{array}{c}0.572 \\
{[0.575]}\end{array}$ \\
\hline $\begin{array}{l}\text { F Test of Joint Orthogonality } \\
\text { [p-values] }\end{array}$ & & & $\begin{array}{c}1.099 \\
{[0.357]}\end{array}$ \\
\hline
\end{tabular}

Note: Columns 1-2 report means and standard deviations (in parenthesis). Column 3 displays the OLS coefficients of the number of neighboring (within $5 \mathrm{~km}$ ) evaluation localities after controlling for the number of neighboring (within 5km) non-evaluation Progresa localities along with the associated p-values (in brackets). State fixed effects are included in all specifications. Standard errors are clustered at the level of groupings of partially overlapping neighborhoods. 


\section{B Consistency of the OLS coefficients When One or More Regressor is Endogenous}

A general writing of the linear regression model we consider is

$$
y=x_{1} \beta_{1}+x_{2} \beta_{2}+u
$$

where $x_{2}$ is a matrix of endogenous explanatory variables, i.e. $E\left(x_{2}^{\prime} u\right) \neq 0$ and $x_{1}$ is a matrix of explanatory variables that are exogenous, i.e. i.e. $E\left(x_{1}^{\prime} u\right)=0 . \beta_{1}$ and $\beta_{2}$ are (column) vectors of coefficients and $u$ is a vector of the error terms.

In our specific case, $x_{2}$ is the number of potential beneficiary villages $N_{P}$, while $x_{1}$ is the number of actual beneficiary villages $N_{B}$. While $N_{B}$ is correlated with treatment density and hence potentially associated with unobserved determinants of outcomes captured by the residual $u$ in an unconditional model, it is not anymore when we control for $N_{P}$. This is because the residual variation in $N^{B}$ is then solely determined by the random number of treatment group villages in the neighborhood. The model we estimate is formally similar to the general model above, as the same estimates can be obtained using the variables $N^{C}$ and $N^{P}$, and $N^{C}$ is exogenous while $N^{P}$ is endogenous; we indeed have:

$$
y=\beta_{1} N^{B}+\beta_{2} N^{P}+u=\beta_{1}\left(N^{P}-N^{C}\right)+\beta_{2} N^{P}+u=-\beta_{1} N^{C}+\left(\beta_{1}+\beta_{2}\right) N^{P}+u
$$

Using the partitioned matrix notation, the vector of OLS coefficients is given by

$$
\left(\begin{array}{c}
\hat{\beta}_{1} \\
\hat{\beta}_{2}
\end{array}\right)=\left(\begin{array}{ll}
x_{1}^{\prime} x_{1} & x_{1}^{\prime} x_{2} \\
x_{2}^{\prime} x_{1} & x_{2}^{\prime} x_{2}
\end{array}\right)^{-1}\left(\begin{array}{c}
x_{1}^{\prime} \\
x_{2}^{\prime}
\end{array}\right) u
$$

Since $x_{2}$ is random conditional on $x_{1}$, it follows that the two set of explanatory variables are uncorrelated with each others: $E\left(x_{1}^{\prime} x_{2}\right)=0$. Hence, the variance $V\left(x_{1}, x_{2}\right)$ of the full set of covariates in the right-hand side term converges asymptotically to

$$
\left(\begin{array}{cc}
x_{1}^{\prime} x_{1} & x_{1}^{\prime} x_{2} \\
x_{2}^{\prime} x_{1} & x_{2}^{\prime} x_{2}
\end{array}\right) \rightarrow\left(\begin{array}{cc}
E\left(x_{1}^{\prime} x_{1}\right) & 0 \\
0 & E\left(x_{2}^{\prime} x_{2}\right)
\end{array}\right)
$$

Using the independence of $x_{2}$ from $u$, the product of the last two terms converges to

$$
\left(\begin{array}{l}
x_{1}^{\prime} \\
x_{2}^{\prime}
\end{array}\right) u \rightarrow\left(\begin{array}{c}
E\left(x_{1}^{\prime} u\right) \\
0
\end{array}\right)
$$

So the vector of coefficients converges asymptotically to

$$
\left(\begin{array}{c}
\hat{\beta}_{1} \\
\hat{\beta}_{2}
\end{array}\right) \rightarrow\left(\begin{array}{c}
\beta_{1} \\
\beta_{2}
\end{array}\right)+\left(\begin{array}{c}
E\left(x_{1}^{\prime} x_{1}\right)^{-1} E\left(x_{1}^{\prime} u\right) \\
0
\end{array}\right)
$$

To summarize, the OLS coefficients $\hat{\beta}_{2}$ are consistent estimates of the marginal effects of the exogenous variables, $\beta_{2}$. On the other hand, the OLS coefficients on the endogenous variables $\hat{\beta}_{1}$ are biased, due for instance to omitted variables, but this bias does not contaminate the 
coefficients estimated for the exogenous variables to the extent that those are uncorrelated with the endogenous variables. In our setting, this is likely the case because the partial variation in $N^{B}$ (i.e. after netting out the effect of $N^{P}$ ) solely captures the randomized allocation into treatment of evaluation localities.

\section{Additional References}

Progresa (1997). "Nota Tecnica: Diseño Muestra Basal y Control", Technical Note. 